\title{
The Influence of Above-Ground Herbivory on the Response of Arctic Soil Methanotrophs to Increasing $\mathrm{CH}_{4}$ Concentrations and Temperatures
}

\author{
Edda M. Rainer ${ }^{1, *}$, Christophe V. W. Seppey ${ }^{1,2}$, Caroline Hammer ${ }^{1}$, Mette M. Svenning ${ }^{1}$ \\ and Alexander T. Tveit ${ }^{1}$ (D) \\ 1 Department of Arctic and Marine Biology, UiT, The Arctic University of Norway, 9037 Troms $\varnothing$, Norway; \\ seppey@uni-potsdam.de (C.V.W.S.); c.hammer@boku.ac.at (C.H.); mette.svenning@uit.no (M.M.S.); \\ alexander.t.tveit@uit.no (A.T.T.) \\ 2 Institute of Environmental Sciences and Geography, University of Potsdam, Karl-Liebknecht-Str. 24-25, \\ 14476 Potsdam, Germany \\ * Correspondence: edda.m.rainer@uit.no
}

Citation: Rainer, E.M.;

Seppey, C.V.W.; Hammer, C.; Svenning, M.M.; Tveit, A.T. The Influence of Above-Ground Herbivory on the Response of Arctic Soil Methanotrophs to Increasing $\mathrm{CH}_{4}$ Concentrations and Temperatures. Microorganisms 2021, 9 , 2080. https://doi.org/10.3390/ microorganisms 9102080

Academic Editor: Vitaly V. Kadnikov

Received: 27 August 2021

Accepted: 23 September 2021

Published: 2 October 2021

Corrected: 8 December 2021

Publisher's Note: MDPI stays neutral with regard to jurisdictional claims in published maps and institutional affiliations.

Copyright: (c) 2021 by the authors. Licensee MDPI, Basel, Switzerland. This article is an open access article distributed under the terms and conditions of the Creative Commons Attribution (CC BY) license (https:/ / creativecommons.org/licenses/by/ $4.0 /)$.

\begin{abstract}
Rising temperatures in the Arctic affect soil microorganisms, herbivores, and peatland vegetation, thus directly and indirectly influencing microbial $\mathrm{CH}_{4}$ production. It is not currently known how methanotrophs in Arctic peat respond to combined changes in temperature, $\mathrm{CH}_{4}$ concentration, and vegetation. We studied methanotroph responses to temperature and $\mathrm{CH}_{4}$ concentration in peat exposed to herbivory and protected by exclosures. The methanotroph activity was assessed by $\mathrm{CH}_{4}$ oxidation rate measurements using peat soil microcosms and a pure culture of Methylobacter tundripaludum SV96, qPCR, and sequencing of pmoA transcripts. Elevated $\mathrm{CH}_{4}$ concentrations led to higher $\mathrm{CH}_{4}$ oxidation rates both in grazed and exclosed peat soils, but the strongest response was observed in grazed peat soils. Furthermore, the relative transcriptional activities of different methanotroph community members were affected by the $\mathrm{CH}_{4}$ concentrations. While transcriptional responses to low $\mathrm{CH}_{4}$ concentrations were more prevalent in grazed peat soils, responses to high $\mathrm{CH}_{4}$ concentrations were more prevalent in exclosed peat soils. We observed no significant methanotroph responses to increasing temperatures. We conclude that methanotroph communities in these peat soils respond to changes in the $\mathrm{CH}_{4}$ concentration depending on their previous exposure to grazing. This "conditioning" influences which strains will thrive and, therefore, determines the function of the methanotroph community.
\end{abstract}

Keywords: methanotroph; methane oxidation; pmoA amplicon sequencing; Methylobacter; grazing pressure; peat soil microcosms; temperature; Arctic

\section{Introduction}

Vegetation in parts of the Arctic has changed severely due to increased grazing by geese [1-3]. The higher geese numbers are closely linked to climate and land-use changes, as food sources are increasing in their overwintering grounds [4,5]. Herbivory-induced changes in vegetation lead to changes in below-ground biota and their productivity [6-8] and affect the balance of greenhouse gases in wetlands, with higher methane $\left(\mathrm{CH}_{4}\right)$ emissions from areas subjected to grazing [8-11]. The exclusion of herbivores from patches of Arctic peatlands led to the restoration of vascular plant growth [12], and it was shown that higher abundances of vascular plants alter the polysaccharide composition in these soils, further changing the soil microbial community [13].

At the same time, the Arctic is warming two to three times faster than the global average, an effect known as Arctic amplification [14-16]. A result of this is the acceleration of permafrost thaw and a thickening of the active layer, with longer periods of non-frozen topsoil [17]. Thawing permafrost contains organic carbon, which can be metabolized 
by microbes that emit carbon dioxide $\left(\mathrm{CO}_{2}\right)$ and $\mathrm{CH}_{4}$. It has been shown that even small increases in temperatures can lead to substantial increases in $\mathrm{CH}_{4}$ production by peat soil microorganisms under anoxic conditions [18-21]. Increased $\mathrm{CH}_{4}$ production can potentially lead to increased $\mathrm{CH}_{4}$ emissions, further increasing global temperatures through radiative forcing.

$\mathrm{CH}_{4}$ production is counterbalanced by methane-oxidizing bacteria (MOB; methanotrophs). $\mathrm{MOB}$ act as a biological filter for $\mathrm{CH}_{4}$ and play a key role in mitigating $\mathrm{CH}_{4}$ emissions from peat and other soils. Many MOB live at the oxic/anoxic interface in peatland soils [22,23], oxidizing $\mathrm{CH}_{4}$ for energy harvest and biomass synthesis. MOB are a diverse group of bacteria belonging to the phyla Gamma- and Alphaproteobacteria and Verrucomicrobia [24]. The diversity of MOB communities is affected by environmental variables such as $\mathrm{pH}$ and oxygen $\left(\mathrm{O}_{2}\right)$. Many cold and neutral $\mathrm{pH}$ soils are inhabited by low-diversity communities of MOB, dominated by the genus Methylobacter, e.g., [25-27]. In contrast, cold acidic soils are more likely to be dominated by members of the Alphaproteobacteria, such as the genera Methylocystis and Methylocapsa [24,28-30].

MOB found in Arctic soils have temperature growth patterns ranging from psychrotrophic to mesophilic; these MOB communities can, therefore, respond to large temperature changes [26,31-33]. However, physiological and ecological temperature responses and how these affect community $\mathrm{CH}_{4}$ oxidation rates are not well understood. In line with our limited understanding of this, studies have shown that temperature effects on $\mathrm{CH}_{4}$ oxidation rates are inconsistent, ranging from, for example, strong temperature responses in landfill soils [34] to variable responses in permafrost soils [35] and a lack of responses in forest soils [36]. On the contrary, the physiological responses of different MOB species to temperature based only on growth are highly predictable [37]. The relationship between temperature, growth rates, and soil $\mathrm{CH}_{4}$ oxidation rates depends on numerous variables, such as soil $\mathrm{CH}_{4}$ and nutrient concentrations, enzyme kinetics, physiological acclimation, and growth responses of individual strains and overall MOB population sizes. Additionally, the types and numbers of different strains responsible for oxidation are also likely to affect $\mathrm{CH}_{4}$ oxidation rates.

Due to the numerous controls on MOB communities and their activities, it may be anticipated that the type of soil habitat strongly influences potential $\mathrm{CH}_{4}$ oxidation rates. In adjacent but chemically and structurally different permafrost soil habitats, different $\mathrm{CH}_{4}$ oxidation rates were observed, with higher rates in soils exposed to the highest $\mathrm{CH}_{4}$ concentrations [35]. Substrate availability, that is, $\mathrm{CH}_{4}$ concentrations, have been shown to control $\mathrm{CH}_{4}$ oxidation rates in both lakes and forest soils [38,39]. Similarly, peat exposed to herbivory displayed differently structured microbiota, including altered MOB habitats and higher $\mathrm{CH}_{4}$ oxidation potentials than peat protected from herbivory by barnacle geese $[13,27]$.

However, it is still unclear how peat $\mathrm{MOB}$ communities respond to changes in temperature and $\mathrm{CH}_{4}$ production. It is also unknown how herbivory influences this response. The objective of this study was to investigate the effect of increasing $\mathrm{CH}_{4}$ concentrations and temperatures on MOB community activities in samples representing two different Arctic peat soil ecosystem states-(1) peat exposed to geese grazing for more than 20 years, and (2) peat protected from grazing for the last 20 years.

\section{Materials and Methods}

\subsection{Field Site and Sampling}

Samples were collected in August 2016 at Solvatn. The Solvatn peatland (N78 55.550, E11 56.611) is located close to the Ny Ålesund research station and settlement in Svalbard. It is heavily grazed by Barnacle geese (Branta leucopsis) and dominated by brown mosses, primarily Calliergon richardsonii [40]. Exclosures established in 1998 protect parts of the peatland vegetation from grazing geese [12], allowing for the growth of vascular plants that are otherwise suppressed by grazing. From one site, named SV1 in a recent study [27], two blocks (approximately $30 \times 15 \times 30 \mathrm{~cm}$ ) were cut from the peat soil protected from 
grazing (SV1 EX1 and SV1 EX2) as well as from the adjacent grazed peat soils (SV1 GR1 and SV1 GR2) and directly transferred to zip-lock plastic bags. All four blocks were kept cool during transportation from the field sites to the on-site laboratory (approximately $5 \mathrm{~min}$ ) and then frozen at $-20^{\circ} \mathrm{C}$ upon arrival. The blocks were further shipped, frozen, to the laboratory in Tromsø, Norway, and stored at $-20{ }^{\circ} \mathrm{C}$ until being used for the microcosm experiments. The experiments were not carried out in the field laboratory due to lacking infrastructure. Consequently, the samples were stored frozen to avoid extended storage in a non-frozen condition that could lead to system changes. These soils are exposed to freezing conditions for most of the year, including freeze and thaw occurrences during spring and autumn. Nevertheless, to evaluate the effects of freezing, $\mathrm{CH}_{4}$ oxidation rates were quantified both immediately after thawing and again after a three-week incubation. We also added an additional pre-incubation period to one of our two experiments to test whether prolonged incubation would lead to even higher oxidation rates. Details of this step are presented in Section 2.2.

\subsection{Soil Microcosms}

This study was based on two peat soil microcosm experiments, referred to as Exp I and Exp II. The microcosms were organized in a fully crossed factor design to study the combined effect of two $\mathrm{CH}_{4}$ concentrations and two temperatures on the two grazing treatments (grazed and exclosed peat).

The zone of maximal $\mathrm{CH}_{4}$ oxidation in the Arctic peat soil, as previously identified in situ [27], was used for the experiments. In grazed soils, this zone was located at a depth of $0.5-2.0 \mathrm{~cm}$, while in exclosed soils, it was located at a depth of 4-8 cm [27].

The experimental temperatures were $8{ }^{\circ} \mathrm{C}$ and $15^{\circ} \mathrm{C}$. The lower temperature of $8{ }^{\circ} \mathrm{C}$ is a frequently encountered surface soil temperature at this high latitude during summer (5.4-10.0 ${ }^{\circ} \mathrm{C}$ for grazed soils and $4.4-9.8^{\circ} \mathrm{C}$ for exclosed soils at a depth of $5 \mathrm{~cm}$, [27]), while $15^{\circ} \mathrm{C}$ is at the high end of temperatures recorded in the vegetation layer of Arctic peat soil in summer $[27,41,42]$. The experimental headspace $\mathrm{CH}_{4}$ concentrations were $0.1 \%$ (about $2 \mu \mathrm{M}$ of dissolved $\mathrm{CH}_{4}$ at $8{ }^{\circ} \mathrm{C}$ and $1.7 \mu \mathrm{M}$ of dissolved of $\mathrm{CH}_{4}$ at $15^{\circ} \mathrm{C}$ ) and $1 \%$ (about $20 \mu \mathrm{M}$ of dissolved $\mathrm{CH}_{4}$ at $8{ }^{\circ} \mathrm{C}$ and about $17 \mu \mathrm{M}$ of dissolved $\mathrm{CH}_{4}$ at $15^{\circ} \mathrm{C}$ ), imitating commonly occurring $\mathrm{CH}_{4}$ concentrations in the upper layers of these soils. Soil $\mathrm{CH}_{4}$ concentrations previously observed ranged from 100.7-237.4 $\mu \mathrm{M}($ avg $153.5 \mu \mathrm{M})$ in grazed sites at a depth of $5 \mathrm{~cm}$ and from $0.4-3.7 \mu \mathrm{M}(\operatorname{avg} 1.5 \mu \mathrm{M})$ in exclosed sites at a depth of $10 \mathrm{~cm}$ [27].

For Exp I, peat blocks were thawed at $8{ }^{\circ} \mathrm{C}$ overnight. Layers $0-2 \mathrm{~cm}$ deep of the grazed peat soil and layers $5-7 \mathrm{~cm}$ deep of the exclosed peat soil were cut from the peat blocks. Then, $4 \mathrm{~g}$ of peat soil were weighed into $50 \mathrm{~mL}$ serum bottles (16 bottles with grazed and 16 bottles with exclosed peat soil). Each vial was closed with butyl rubber stoppers (Wheaton) and aluminum crimp caps [43].

We injected $0.07 \mathrm{~mL} \mathrm{CH}_{4}(95 \%$ v/v) into 16 bottles ( 8 bottles per grazing treatment) to obtain a headspace concentration of $0.1 \% \mathrm{CH}_{4}$, while 16 bottles ( 8 bottles per grazing treatment) were injected with $0.7 \mathrm{~mL} \mathrm{CH}_{4}(95 \% \mathrm{v} / \mathrm{v})$ for a headspace concentration of $1 \% \mathrm{CH}_{4}$. For each grazing treatment, four bottles with $0.1 \% \mathrm{CH}_{4}$ and four bottles with $1 \% \mathrm{CH}_{4}$ were incubated at $8{ }^{\circ} \mathrm{C}$ and at $15^{\circ} \mathrm{C}$, respectively. In total, the experiment consisted of 32 bottles.

At the start of the experiment, the initial $\mathrm{CH}_{4}$ oxidation rates were calculated from four $\mathrm{CH}_{4}$ concentration measurements made within the first $20-40 \mathrm{~h}$ for each bottle. At each time point, $0.5 \mathrm{~mL}$ gas samples were retrieved from the headspace with a pressurelock syringe (Vici Precision Sampling, LA, USA) and injected directly onto a Haysep-D packed column of a GC-FID (SRI Instruments, CA, USA). The elution time was $1.8 \mathrm{~min}$ for $\mathrm{CH}_{4}$, and the instrument was set to maximum sensitivity. The $\mathrm{CH}_{4}$ concentrations were calculated by comparing them to the injected standard gases (Messer, Switzerland). After the first four sampling time-points, an incubation period of three weeks started, during which the $\mathrm{CH}_{4}$ headspace concentrations were maintained at $0.1 \%$ or $1 \%$. The $\mathrm{CH}_{4}$ 
was consumed rapidly in some of the microcosms and was, therefore, supplied at regular intervals to ensure that the concentrations never dropped below $0.05 \%$ or $0.8 \% \mathrm{CH}_{4}$ for the $0.1 \%$ or $1 \%$ conditions, respectively.

At the end of the incubation period, the $\mathrm{CH}_{4}$ oxidation rates were estimated with the four measurements described above for the start of the experiment. After the $\mathrm{CH}_{4}$ oxidation rate measurements, the peat soil from each microcosm was transferred into sterile $15 \mathrm{~mL}$ tubes and flash frozen in liquid $\mathrm{N}_{2}$ to be used for RNA extraction.

After evaluating the results of the first experiment, we decided to perform a second experiment (Exp II) with a slightly altered setup, designed to provide even more certainty on three potentially crucial factors-soil depth, pre-incubation length, and pre-incubation temperature.

Twice the number of microcosm replicates for all conditions (64 bottles in total) were used in Exp II to better represent the variability in potential $\mathrm{CH}_{4}$ oxidation rates between the two grazing treatments. We also included a pre-incubation week at $4{ }^{\circ} \mathrm{C}$ for all microcosms. For the $15{ }^{\circ} \mathrm{C}$ microcosms, this was followed by another pre-incubation week at $8{ }^{\circ} \mathrm{C}$ to avoid abrupt large temperature increases unlikely to occur in nature. Because of this additional week, the microcosms incubated at $15{ }^{\circ} \mathrm{C}$ were incubated for one week longer than the $8{ }^{\circ} \mathrm{C}$ microcosms, while the incubation at the final temperature (i.e., 8 or $15^{\circ} \mathrm{C}$ ) was the same for both sets of microcosms. In Exp II, we targeted a soil layer $4 \mathrm{~cm}$ thick to ensure that the entire zone of the highest $\mathrm{CH}_{4}$ oxidation potential [27] was included. The considerable variation in the $\mathrm{CH}_{4}$ oxidation rates between some replicates in Exp I suggest that the selection of a narrow $2 \mathrm{~cm}$ layer could have excluded the most active zone, in some cases, due to local variations. Therefore, we sampled a layer at a depth of $0-4 \mathrm{~cm}$ for the grazed treatment and at a depth of $4-8 \mathrm{~cm}$ for the exclosed treatment for Exp II. The bottles were then prepared in the same way as for Exp I.

The soil water content was determined gravimetrically by drying $5 \mathrm{~g}$ of soil from each layer at $150{ }^{\circ} \mathrm{C}$ in triplicate. The determined water content was used to calculate the soil dry weight and the $\mathrm{CH}_{4}$ oxidation rate per gram of dry soil for each microcosm.

To consider the different solubility of $\mathrm{CH}_{4}$ in pore water at $8{ }^{\circ} \mathrm{C}$ and $15^{\circ} \mathrm{C}$, the $\mathrm{CH}_{4}$ oxidation rates for the same dissolved concentrations of $\mathrm{CH}_{4}$ were estimated. Assuming first-order rate kinetics, as previously shown in [44], we log-transformed the decline in $\mathrm{CH}_{4}$ over time and fitted linear regression models to the transformed plots. The slopes of the linear models correspond to the rate constants. By multiplying the respective rate constants by a $\mathrm{CH}_{4}$ concentration that would result in the same dissolved $\mathrm{CH}_{4}$ concentrations at 8 and $15^{\circ} \mathrm{C}$, we obtained adjusted rates at these temperatures. The fit of the linear model was evaluated and considered to have a satisfactory coefficient of determination, giving the following values: $\mathrm{R}^{2}-8{ }^{\circ} \mathrm{C}=0.71$ to $0.99, \mathrm{R}^{2}-15^{\circ} \mathrm{C}=0.71$ to $0.99 ; 147$ of the 192 linear models had an $\mathrm{R}^{2}$ of $>0.9$.

\section{3. $\mathrm{CH}_{4}$ Oxidation of Methylobacter Tundripaludum SV96}

M. tundripaludum SV96 was cultivated in NMS medium [45] for 10-14 days at 8 and $15{ }^{\circ} \mathrm{C}$ under a headspace $\mathrm{CH}_{4}$ concentration of approximately $13 \%$ (20 $\mathrm{mL}$ of a mixture of $95 \% \mathrm{CH}_{4}$ and $5 \% \mathrm{CO}_{2}$ ). To reach exponential growth, the culture was transferred to fresh medium three times during this period. Serum bottles were incubated on rotary shakers at $150 \mathrm{rpm}$. Exponentially growing cells were harvested and diluted in sterile $0.5 \mathrm{mM}$ phosphate buffer $(\mathrm{pH}=6.8)$ to a density of about $5 \times 10^{7}$ cells per $\mathrm{ml}$. Then, $21.6 \mathrm{~mL}$ of this diluted cell suspension was distributed into $125 \mathrm{~mL}$ serum bottles ( 3 bottles per concentration and temperature; 24 in total), which were then closed with butyl rubber stoppers (Wheaton) and aluminum crimp caps. Headspace atmospheres were prepared by injecting different amounts of $\mathrm{CH}_{4}\left(0.2,0.6,1.5\right.$, and $3 \mathrm{~mL}$ of $95 \% \mathrm{CH}_{4}$ and $\left.5 \% \mathrm{CO}_{2}\right)$ to create a series of $\mathrm{CH}_{4}$ headspace concentrations (about 1900, 5400, 13,000, and 25,000 ppm, respectively) with three bottles per $\mathrm{CH}_{4}$ concentration. In addition, a negative control that contained only phosphate buffer and no bacterial cells was measured. 
The $\mathrm{CH}_{4}$ concentrations were measured at four time points (including time point zero, right after the headspace preparation) over the course of eight hours. To measure the headspace $\mathrm{CH}_{4}$ concentration, $0.5 \mathrm{~mL}$ of gas was collected with a pressure-lock syringe (VICI) and directly injected into a GC-FID, as was described for the soil microcosms. Starting at time point one, $340 \mu \mathrm{L}$ of cell suspension was collected from each of the bottles after the $\mathrm{CH}_{4}$ measurements to estimate the cell density. The cell density was measured by optical density (OD) at $410 \mathrm{~nm}$. The densities were converted into cell numbers with a standard of cell numbers and OD measurements specifically made for M. tundripaludum SV96. The standard was established by cultivating $M$. tundripaludum SV96 to 14 different optical densities ranging from 0.0085 OD410 to 0.7295 OD410 and counting, for each $\mathrm{OD}$, the number of cells at that optical density using a counting chamber under a light microscope. The cell counts ranged from 6.1 to $726.6 \times 10^{5}$, corresponding to a linear model $\mathrm{R}^{2}$ of 0.92 . The estimation of cell numbers allowed us to adjust the $\mathrm{CH}_{4}$ oxidation rates to the number of cells as this number increased throughout the experiment. Between measurements, the flasks were incubated at the respective temperatures on a rotary shaker at $150 \mathrm{rpm}$ [46].

The headspace and dissolved $\mathrm{CH}_{4}$ concentrations were calculated from the measured peak areas using a range of defined standards. Concentrations were converted into masses of $\mathrm{CH}_{4}$ using the ideal gas law, while Henry's law was used to estimate the corresponding mass of dissolved $\mathrm{CH}_{4}$. All numbers were adjusted for the removal of gases and medium during the sampling. The $\mathrm{CH}_{4}$ oxidation rates calculated between each time point were then normalized to the time between measurements and the number of cells in the medium to obtain a rate ( $\mu \mathrm{mol}$ of $\mathrm{CH}_{4}$ oxidized per $10^{8}$ cells per hour).

Assuming first-order rate kinetics, as previously shown in [44], we log-transformed the cell-normalized decline in $\mathrm{CH}_{4}$ over time and fitted linear regression models to the transformed plots. The slopes of the linear models correspond to the rate constants. By multiplying the respective rate constant by the desired concentration of $\mathrm{CH}_{4}$, we obtained the rates of oxidation at these concentrations [44]. The fit of the linear models was evaluated and considered to have satisfactory coefficients of determination, giving the following values: $\mathrm{R}^{2}-8{ }^{\circ} \mathrm{C}=0.83-0.99, \mathrm{R}^{2}-15{ }^{\circ} \mathrm{C}=0.72-0.99 ; 24$ of the 28 linear models had an $\mathrm{R}^{2}$ of $>0.9$.

\subsection{RNA Extraction}

Nucleic acids were extracted from the peat soil samples from Exp I. The samples were homogenized using a mortar and pestle while suspended in liquid nitrogen. The nucleic acids were extracted from $0.2 \mathrm{~g}$ of peat soil (two technical replicates per sample) using a modified version of Griffiths' protocol [42,47]. For RNA extraction, the two replicates were pooled, and DNA was removed (RQ1 DNase, Promega, Madison, WI, USA), which

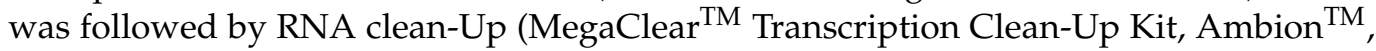
Thermo Fisher Scientific, Waltham, MA, USA) and ethanol precipitation. The RNA quality was controlled by gel electrophoresis and a Nanodrop (Thermo Fisher Scientific, Waltham, MA, USA). The RNA was reverse transcribed using Superscript IV (Thermo Fisher Scientific, Waltham, MA, USA) and the cDNA was used as a template for PCR with the primer pair A189F/mb661R [48] to confirm the presence of the pmoA gene transcript. The cDNA samples were sent for amplicon generation and sequencing with Illumina MiSeq at the IMGM laboratories in Planegg, Germany. For the amplicon generation, both the A189F/mb661 and A189F/A682R primers sets were applied, further referred to as the mb661R and A682R datasets [48,49]. The pmoA transcript amplicons were generated in a 2-step target-specific (TS) PCR (using $10 \mathrm{ng}$ of cDNA as a template) for 25 cycles, followed by a 12-cycle index PCR using $1 \mu \mathrm{L}$ from the TS PCR products. The polymerase used for amplification was the Q5 ${ }^{\circledR}$ High-Fidelity polymerase from NEB (Ipswich, MA, USA). 


\subsection{PmoA Transcript Numbers}

The cDNA samples were diluted to $2.5 \mathrm{ng} / \mu \mathrm{L}$ for quantification with qPCR. For the standard curve, genomic DNA of $M$. tundripaludum SV96 was checked for integrity using gel electrophoresis and quantified using Qubit Fluorometric Quantification (Thermo Fischer Scientific, Waltham, MA, USA). Copy numbers of $p m o A$ were calculated based on genomic information and the measured concentration. The standard curve was generated using dilutions of the DNA from M. tundripaludum SV96, yielding $7.15 \times 10^{6}$ to $7.15 \mathrm{pmoA}$ copies. The diluted cDNA samples and the diluted standards were analyzed in triplicate. The negative controls (no template) were analyzed simultaneously in at least six replicates. The master mix and primer for the qPCR were the SsoFast Evergreen Supermix (Biorad, Hercules, CA, USA) and the A189/mb661R primer pair [48], respectively. The thermal profile for qPCR amplification [50] was used with the following modifications: Fluorescence data acquisition was performed at $78^{\circ} \mathrm{C}$ for $30 \mathrm{~s}$, and a total of 35 cycles were performed after the initial 10 cycles of touchdown qPCR. Melting curve analysis was performed from $65^{\circ} \mathrm{C}$ to $95^{\circ} \mathrm{C}$. The calculations for each replicate were performed within the qPCR software (CFX Manager, Biorad, Hercules, CA, USA) based on the standard curve. The number of $p m o A$ transcripts per gram of dry soil was calculated based on the average of the three replicates.

\subsection{Bioinformatics}

\subsubsection{Databases}

For the taxonomical assignation, a de-replicated database was built with sequences trimmed according to the corresponding $p m o A$ primer sets. Sequences used for the two pmoA databases [51] were complemented with three Methylobacter sequences (GenBank $\mathrm{id}=\mathrm{AJ} 414658.1, \mathrm{KC} 878619.1$, and the sequence from an Arctic coalmine isolate from Svalbard (not published)).

\subsubsection{Pipeline}

Reads were merged using the program Flash (v. 1.2.8; [52]) and low-quality sequences were discarded if they had a 50 nucleotide fragment with an average Phred score below 20 prior to trimming the primers. Chimeras were removed using the program Vsearch (v. 2.4.4; [53]), both against a database (for $p m o A$ primers [51]) and de novo. To avoid frameshift errors, only sequences without stop codon errors or framing errors (the nucleotide number is not divisible by three) were kept. OTU clustering was performed using Swarm (v. 2.1.13; [54]), and taxonomically assigned using the best alignment between the dominant sequence of each OTU and the database, using Ggsearch36 (v. 36.3.8f; [55]). Finally, the OTUs were selected according to their dominant sequence length (mb661: $(465,474))$, A682: $(492,495))$ to remove obvious sequencing errors. An overview of all the steps in the pipeline is given in Supplementary Table S1.

\subsubsection{Community Analyses}

To normalize for sequencing depth, we used the relative abundance of the two MOB communities. To avoid noise caused by low-abundance OTUs in a given sample, every OTU representing less than a thousandth of the community in this sample was considered as absent from that sample. This denoising step removed less than $5 \%$ of the reads.

\subsubsection{Redundancy Analysis (RDA)}

Prior to analyses, the community matrices were log-normalized according to the methods of [56] (function decostand, package vegan v. 2.4-2; [57]). For each primer pair, the effects of elevated $\mathrm{CH}_{4}$ and elevated temperature were estimated for the microbial communities using a redundancy analysis (RDA, function capscale, package vegan v. 2.4-2; [57]). To only consider the effect of the $\mathrm{CH}_{4}$ and temperature treatments, the effects of the peat block replicates were considered random variables. The effect of the factors, as well as the significance of the ordination axes were tested with a permutation test 
(10,000 permutations, function anova.cca, package vegan v. 2.4-2; [57]). To disentangle the effects of interactions between the grazing treatments, an RDA was calculated for each grazing treatment and tested in the same fashion as the analysis performed on all samples.

\subsubsection{Bioindicators}

For each primer pair and grazing treatment, the "responding bioindicator OTUs" for both $\mathrm{CH}_{4}$ concentrations were identified using an indicator species analysis (indval; function indval, package labdsv v. 1.8-0; [58]). An OTU was selected as a "responding bioindicator OTU" if the probability of reaching a higher indicator value than that of the bioindicator after 10,000 permutations was lower than 0.01 . "Responding bioindicator OTUs" were only reported in heatmaps.

We further selected the "unconditional bioindicator OTUs" by one of two criteria-(1) OTUs that respond to either $0.1 \%$ or $1 \% \mathrm{CH}_{4}$ in both the grazed and exclosed peat soil microcosms; (2) OTUs that respond to either $0.1 \%$ or $1 \% \mathrm{CH}_{4}$ in the grazed peat soil and are absent from exclosed peat soil microcosms, or the other way around.

\subsubsection{Phylogenetic Analysis}

For the phylogenetic analysis, only "unconditional bioindicator OTUs" were included. Phylogenetic trees were then built from the "unconditional bioindicator OTU" sequences and closely related sequences were retrieved from the NCBI GenBank to better assess their taxonomy. These closely related sequences were obtained by aligning the bioindicator sequences (using BLASTn) against the NCBI nucleotide database and selecting the two-highest scoring matches. A set of cultivated gammaproteobacterial MOB sequences were retrieved in addition to a set of $p m o A$ sequences belonging to upland-soil cluster (USC)-gamma, the latter serving as an outgroup to root the tree. Sequences were aligned in MEGA10 [59] using MUSCLE with UPGMB clustering [60]. The length of the alignment was inspected visually for an overlap in all sequences and a section of $452 \mathrm{bp}$ (the mb661R dataset) was chosen for phylogenetic analysis. A phylogenetic tree was constructed in MEGA10 using the neighbor-joining method with the Jukes-Cantor correction and 500 bootstraps [59]. In addition, phylogenetic trees using the maximum likelihood and the minimum evolution method (with the Jukes-Cantor correction and 500 bootstraps each) were generated and compared to the first tree.

\section{Results}

\section{1. $\mathrm{CH}_{4}$ Oxidation Rates Changing in Response to $\mathrm{CH}_{4}$ Concentrations}

Incubation under microcosm headspace atmospheres with $1 \% \mathrm{CH}_{4}$ resulted in higher $\mathrm{CH}_{4}$ oxidation rates than with $0.1 \% \mathrm{CH}_{4}$ for both grazed and exclosed peat soils. This effect was observed both before and after the three-week incubation period (Figure 1 and Supplementary Figure S1). Additionally, the $\mathrm{CH}_{4}$ oxidation rates were always higher after the three-week incubation (Supplementary Figures S2 and S3), showing that the MOB community responded positively to prolonged incubation at stable conditions after thawing. However, the oxidation rates after the three-week incubation period were similar in Exp I (Supplementary Figure S2) and Exp II (Supplementary Figure S3), confirming that the additional pre-incubation at $4{ }^{\circ} \mathrm{C}$ and $8{ }^{\circ} \mathrm{C}$ in Exp II had negligible effects on the $\mathrm{CH}_{4}$ oxidation rate. This suggests that within the first three weeks, this MOB community had reached its full potential under the present conditions. Overall, higher $\mathrm{CH}_{4}$ oxidation rates were observed in the grazed peat soils. 


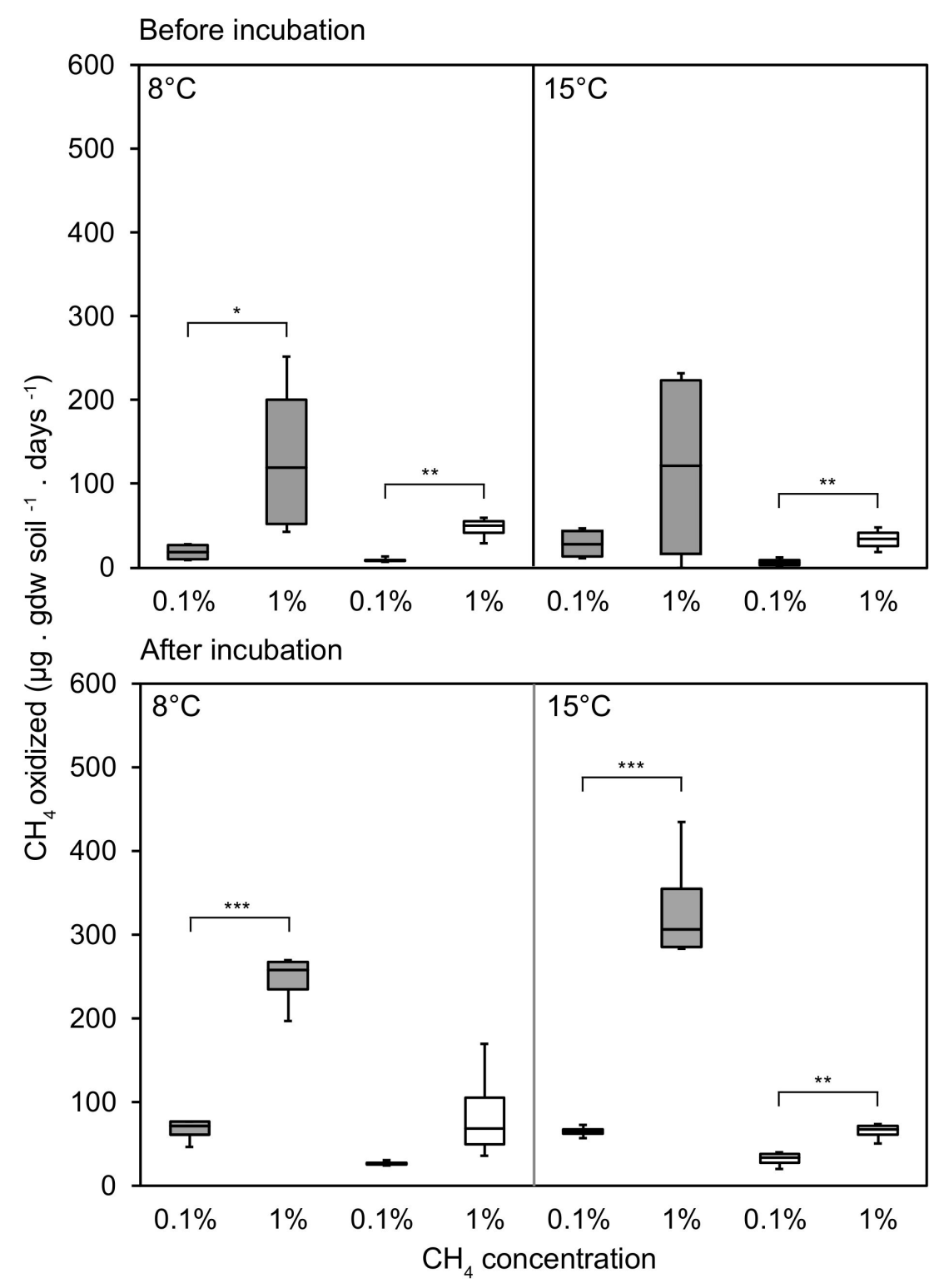

Figure 1. $\mathrm{CH}_{4}$ oxidation rates from Exp I, emphasizing the comparison between $0.1 \%$ and $1 \%$ headspace $\mathrm{CH}_{4}$ concentrations. Results are shown for measurements collected before (top) and after (bottom) the three-week incubation period, and at 8 (left) and $15^{\circ} \mathrm{C}$ (right). Grazed microcosms are shown in gray; exclosed microcosms in white. Comparison using linear mixed models with peat blocks as random variables shows significant differences in the $\mathrm{CH}_{4}$ oxidation rates between $\mathrm{CH}_{4}$ concentrations $\left({ }^{*} p<0.05 ;{ }^{* *} p<0.01\right.$; $\left.{ }^{* * *} p<0.001\right)$.

\section{2. $\mathrm{CH}_{4}$ Oxidation in Response to Temperature}

We observed mostly minor and insignificant temperature effects on $\mathrm{CH}_{4}$ oxidation rates in grazed and exclosed peat soils, both before and after the three-week incubation (Figure 2 and Supplementary Figure S4). Exceptions to this were the significantly higher $\mathrm{CH}_{4}$ oxidation rates at $15{ }^{\circ} \mathrm{C}$ compared to $8{ }^{\circ} \mathrm{C}$ in grazed peat soils at $0.1 \% \mathrm{CH}_{4}$ before the three-week incubation in both experiments. In exclosed peat soils from Exp II, significantly higher $\mathrm{CH}_{4}$ oxidation rates at $15{ }^{\circ} \mathrm{C}$ were also measured at $1 \% \mathrm{CH}_{4}$ before the incubation, while significantly lower rates were measured in exclosed peat soil microcosms at $0.1 \%$ $\mathrm{CH}_{4}$ after the incubation. 


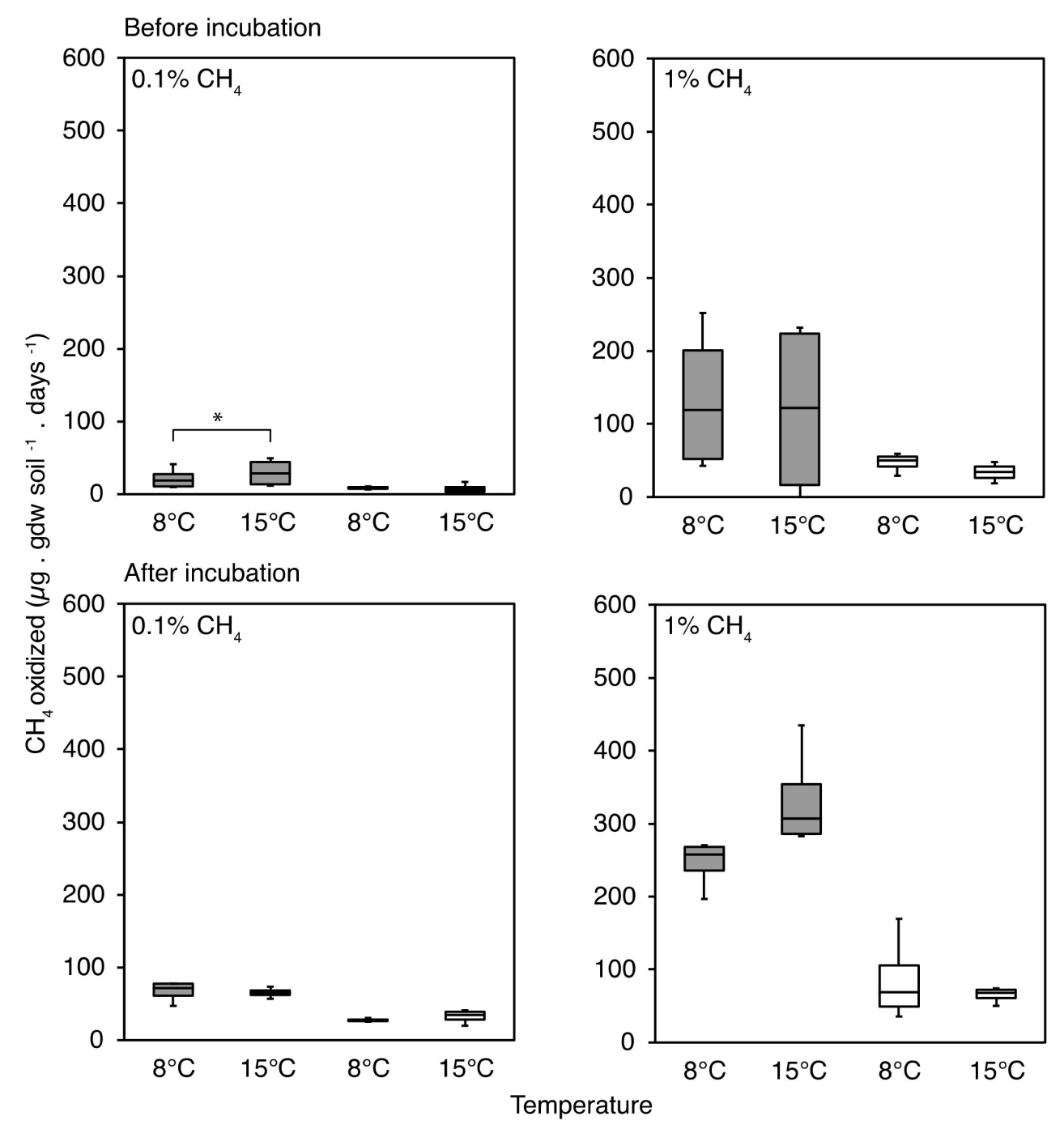

Figure 2. $\mathrm{CH}_{4}$ oxidation rates from Exp I, emphasizing the comparison between $8{ }^{\circ} \mathrm{C}$ and $15{ }^{\circ} \mathrm{C}$. Results are shown for measurements collected before (top) and after (bottom) the three-week incubation period, and at $0.1 \%$ (left) and $1 \% \mathrm{CH}_{4}$ (right). Grazed microcosms are shown in gray; exclosed microcosms in white. Comparison using linear mixed models with peat blocks as random variables shows significant differences in the $\mathrm{CH}_{4}$ oxidation rates between temperatures ${ }^{*} p=0.05-0.01$ ).

\section{3. $\mathrm{CH}_{4}$ Oxidation in a Pure Culture of M. Tundripaludum SV96 in Response to Temperature}

M. tundripaludum SV96 was isolated from the peat soil habitat sampled for the experiments above [32]. To better understand the soil oxidation rates and temperature responses described above, we designed a $\mathrm{CH}_{4}$ oxidation experiment with $\mathrm{M}$. tundripaludum SV96 using the same two temperatures $\left(8^{\circ} \mathrm{C}\right.$ and $\left.15^{\circ} \mathrm{C}\right)$ and $\mathrm{CH}_{4}$ concentrations $(0.1 \%$ and $1 \%)$ for comparison. We observed the highest $\mathrm{CH}_{4}$ oxidation rates per cell number at $1 \% \mathrm{CH}_{4}$ concentration and we also observed a clear effect of temperature at this concentration, with approximately twice as high $\mathrm{CH}_{4}$ oxidation rates at $15^{\circ} \mathrm{C}$ compared to $8{ }^{\circ} \mathrm{C}$ (Figure 3 ). 


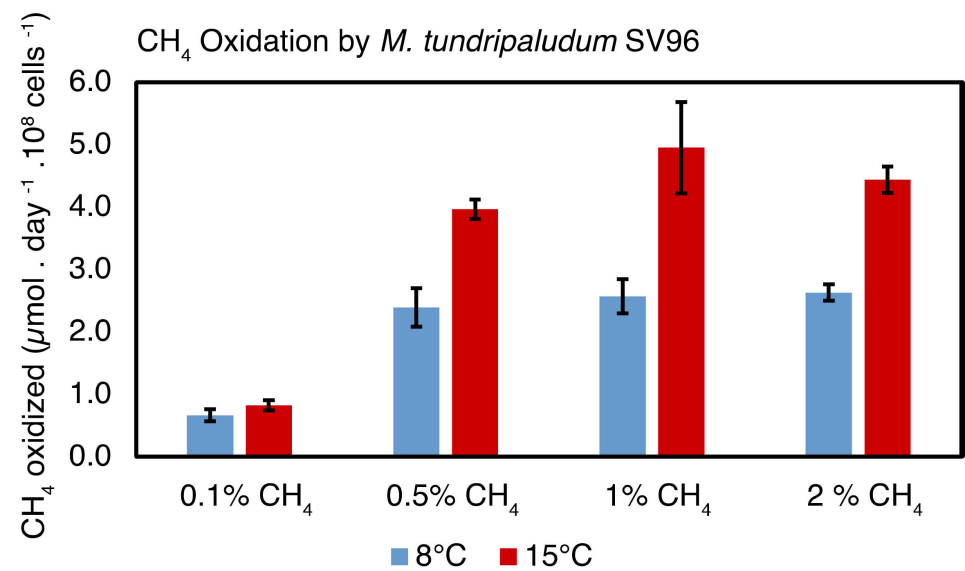

Figure 3. $\mathrm{CH}_{4}$ oxidation per cell for Methylobacter tundripaludum SV96 at $8{ }^{\circ} \mathrm{C}$ (blue) and $15^{\circ} \mathrm{C}$ (red) with $\mathrm{CH}_{4}$ headspace concentrations ranging from $0.1 \%$ to $2 \%$.

However, the temperature effect on the $\mathrm{CH}_{4}$ oxidation rate at $0.1 \%$ headspace concentration was much smaller and not significant $(p=0.3)$. Adjusting the rate according to the $\mathrm{CH}_{4}$ solubility, we observed a similarly small but significant difference ( $p=0.006$, Supplementary Figure S7).

\subsection{MOB Community}

\subsubsection{PmoA Transcript Numbers}

A higher number of $p m o A$ transcripts at $1 \% \mathrm{CH}_{4}$ than at $0.1 \% \mathrm{CH}_{4}$ was detected in the grazed peat soils. This difference was significant at $15^{\circ} \mathrm{C}$ (linear mixed model $(\mathrm{lmm})$ $p=0.04)$, but not at $8^{\circ} \mathrm{C}(\operatorname{lmm} p=0.28)$ (Figure 4). In the exclosed peat soils, no significant differences in $p m o A$ transcript numbers related to the $\mathrm{CH}_{4}$ concentration were detected. Overall, the $p m o A$ transcript numbers were lower for the exclosed peat soils than for the grazed peat soils $\left(0.1 \% \mathrm{CH}_{4} \operatorname{lmm} p=0.04\right.$ at $15{ }^{\circ} \mathrm{C} ; 1 \% \mathrm{CH}_{4} \operatorname{lmm} p=0.01$ at $8{ }^{\circ} \mathrm{C}$, and $p=0.02$ at $\left.15^{\circ} \mathrm{C}\right)$. An exception was found at $0.1 \% \mathrm{CH}_{4}$ at $8{ }^{\circ} \mathrm{C}(\operatorname{lmm} p=0.07)$, suggesting a transcriptionally less active MOB community was responsible for the lower $\mathrm{CH}_{4}$ oxidation rates in the exclosed peat soils.

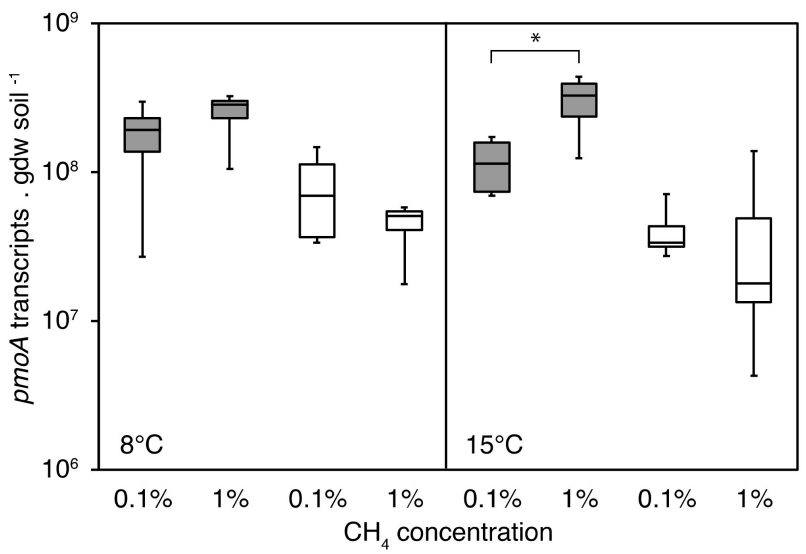

Figure 4. $\mathrm{MOB}$ pmoA transcript number after the three-week incubation at $0.1 \%$ and $1 \% \mathrm{CH}_{4}$ in grazed (gray) and exclosed sites (white). The left panel shows microcosms incubated at $8{ }^{\circ} \mathrm{C}$ and the right panel shows microcosms incubated at $15^{\circ} \mathrm{C}$. The y-axis shows $p m o A$ transcript numbers per gram dry soil, log-transformed. Pairwise comparison using linear mixed models with peat blocks as random variables shows significant differences in the $p m o A$ transcripts $\left({ }^{*} p=0.05-0.01\right)$. 


\subsubsection{Transcriptionally Active $\mathrm{MOB}$}

The active $\mathrm{MOB}$ communities were identified by sequencing $p m o A$ transcripts from Exp I. The $\mathrm{CH}_{4}$ concentration had a significant effect on the composition of MOB community transcripts ( $p<0.001$ for both the mb661R and the A682R dataset) (Figure 5 and Supplementary Figure S8). Temperature, on the other hand, had no significant effect on the MOB community transcript composition ( $p=0.264$ for mb661R and $p=0.449$ for A682R datasets).

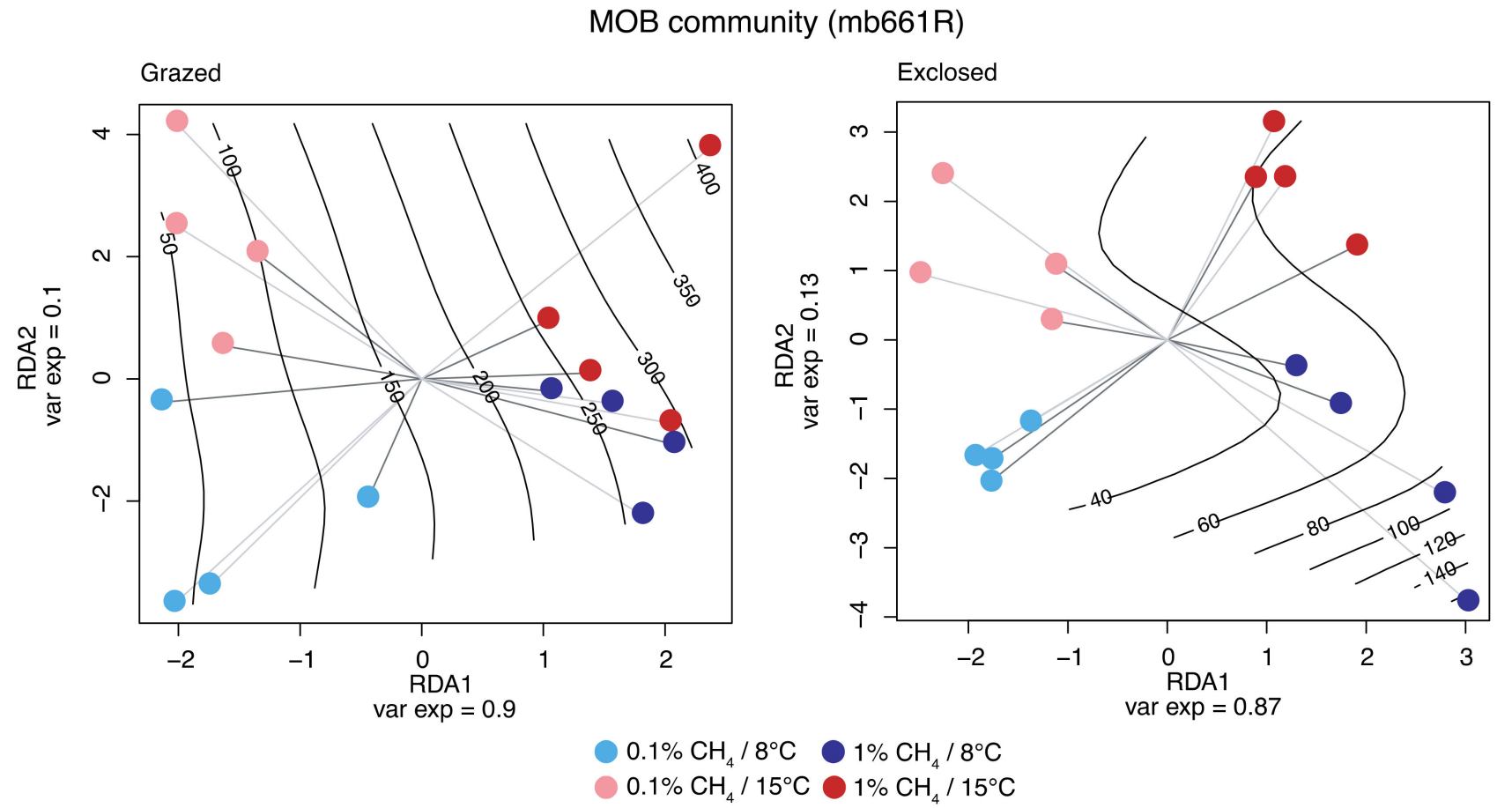

Figure 5. Redundancy analysis of the effect of $\mathrm{CH}_{4}$ concentration and temperature on the MOB communities after incubation ( $p m o A$ transcripts using the A189F/mb661R primer pair). The effect of $\mathrm{CH}_{4}$ concentration and temperature was corrected according to the peat block replicates (represented by gray shaded lines). Samples are labeled according to $\mathrm{CH}_{4}$ concentration (light colors $-0.1 \% \mathrm{CH}_{4}$, dark colors $-1 \% \mathrm{CH}_{4}$ ) and temperature (blue $-8{ }^{\circ} \mathrm{C}$ and red $-15{ }^{\circ} \mathrm{C}$ ). The black lines indicate a projection of the measured $\mathrm{CH}_{4}$ oxidation rates ( $\mu \mathrm{g}$ of $\mathrm{CH}_{4}$ oxidized per gram dry soil and day).

The majority of the detected MOB pmoA transcripts in both the mb661R and the A682R dataset belonged to the family Methylococcacaea (Figure 6 and Supplementary Figure S9). However, the samples incubated at $0.1 \% \mathrm{CH}_{4}$ contained smaller fractions of Methylococcacaea than the samples incubated at $1 \% \mathrm{CH}_{4}$ (Figure 6 and Supplementary Figure S9).

Methylobacter OTUs dominated the $0.1 \% \mathrm{CH}_{4}$ incubations with average relative abundances of $48.9 \%$ (grazed soils) and $44.7 \%$ (exclosed soils) (Figure 6, mb661R). In the $1 \% \mathrm{CH}_{4}$ incubations, Methylobacter OTUs made up even larger fractions, with abundances of $71.8 \%$ (grazed soils) and 68.4\% (exclosed soils) (Figure 6). Contrary to Methylobacter, OTUs within Methylomicrobium and unclassified Type 1a MOB OTUs had higher relative abundances in the $0.1 \% \mathrm{CH}_{4}$ incubations than in the $1 \% \mathrm{CH}_{4}$ incubations.

Similar observations were made in the A682R dataset (Supplementary Figure S9). The lowest relative abundances of Methylobacter pmoA transcripts were observed at $0.1 \% \mathrm{CH}_{4}$, making up $60.9 \%$ (grazed soils) and $72.9 \%$ (exclosed soils). In the $1 \% \mathrm{CH}_{4}$ incubations, Methylobacter OTUs made up larger fractions of 75.9\% (grazed soils) and 79.9\% (exclosed soils). Methylosarcina pmoA transcripts, which were not detected in the mb661R dataset, had the highest relative abundances in the $0.1 \% \mathrm{CH}_{4}$ incubations, with $37.6 \%$ (grazed soils) and $12.3 \%$ (exclosed soils). At $1 \% \mathrm{CH}_{4}$, these OTUs made up only $21.8 \%$ (grazed soils) and $7.7 \%$ (exclosed soils). 

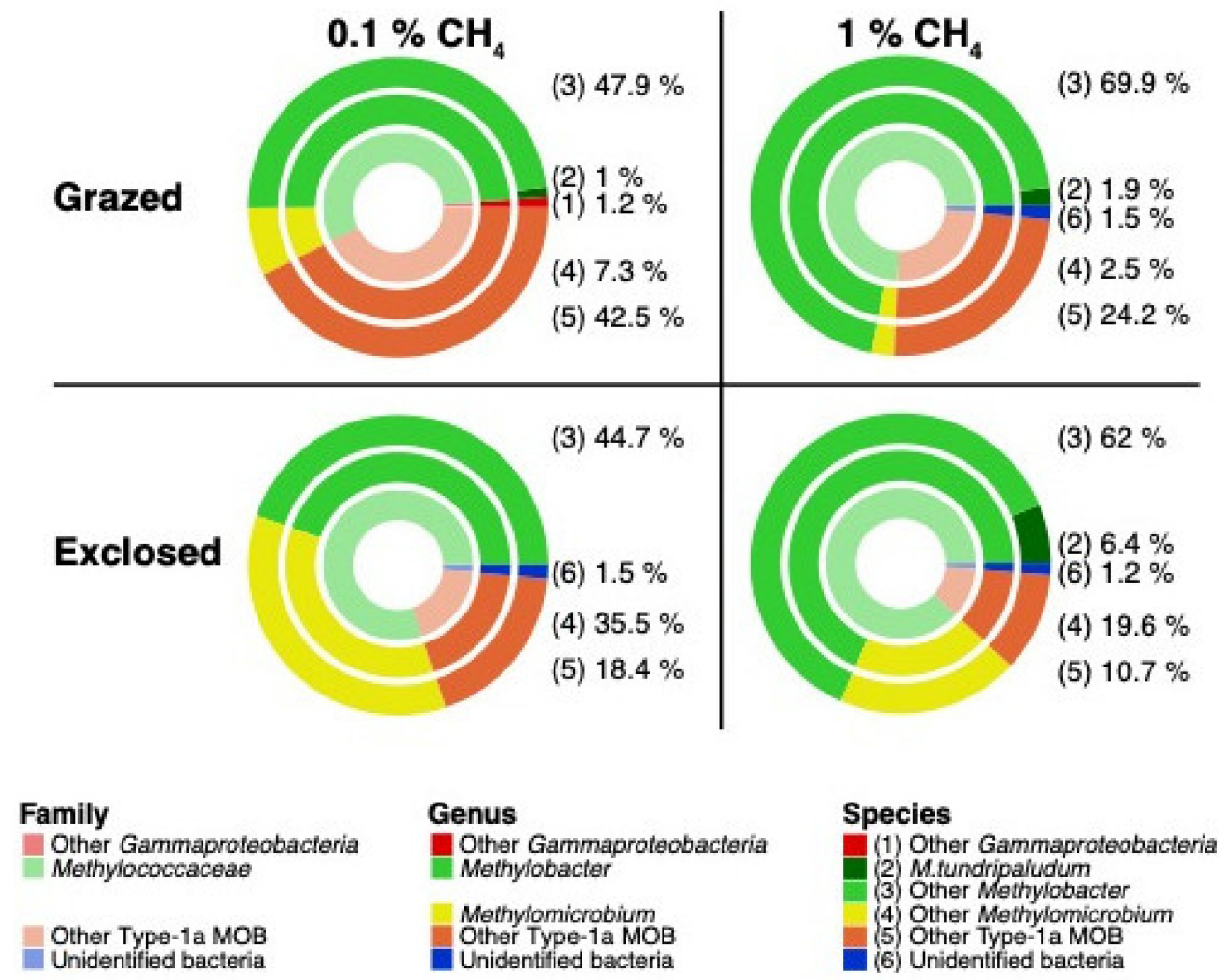

Figure 6. Distribution of MOB taxa (A189F/mb661R primer set) in grazed and exclosed peat soils after incubation at $0.1 \% \mathrm{CH}_{4}$ and at $1 \% \mathrm{CH}_{4}$ (16 soil samples per concentration and 16 soil samples per grazing condition). As temperature had no significant effect on the MOB community, these 16 samples include both the 8 and $15^{\circ} \mathrm{C}$ incubations. OTU clustering was performed using Swarm [54] and taxonomically assigned by using the best alignment between the dominant sequence of each OTU and the database using Ggsearch36 [55]. Taxa with a relative abundance of $>1 \%$ are represented at the full taxonomic resolution, whereas those taxa not reaching the $1 \%$ threshold were added to their broader taxonomic group, one level lower in taxonomic resolution. The different rings represent different taxonomic levels from family to genus to species, moving from the innermost ring outward. Relative abundances for the species level are given in \%.

In the $0.1 \% \mathrm{CH}_{4}$ incubations, the relative abundances of OTUs matching M. tundripaludum SV96 were 1.0\% (grazed soils) and $<1.0 \%$ (exclosed soils) (Figure 6, mb661R dataset). In the $1 \% \mathrm{CH}_{4}$ incubations, the relative abundances were higher, at $1.9 \%$ (grazed soils) and $6.4 \%$ (exclosed soils). The same patterns were observed in the A682R dataset (Supplementary Figure S9), with $<1.0 \%$ (grazed and exclosed soils) and $>4.2 \%$ (grazed and exclosed soils) at $1 \% \mathrm{CH}_{4}$. This shows that $M$. tundripaludum $\mathrm{SV} 96$ is a small but active part of the $\mathrm{MOB}$ community in these soils at high $\mathrm{CH}_{4}$ concentrations.

To identify the MOB OTUs that were preferentially activated by either $0.1 \%$ or $1 \% \mathrm{CH}_{4}$, we screened our datasets for OTUs that were consistently more abundant at one or the other $\mathrm{CH}_{4}$ concentration and called them "responsive bioindicator OTUs". From those OTUs, we selected the OTUs that behaved the same in the grazing treatments (grazed and exclosed peat soil) or that were only present in one of the treatments and called those "unconditional bioindicator OTUs" (see Section 2.6.5. for details about the bioindicator selection).

In the grazed soils, we identified 12 "responsive bioindicator OTUs". Seven (mb661R) and three (A682R) OTUs had higher relative abundances at $0.1 \% \mathrm{CH}_{4}$, and one OTU in each of the datasets (mb661R and A682R) had a higher relative abundance at $1 \% \mathrm{CH}_{4}$ (Figures 7 and 8 and Supplementary Figures S10 and S11). In the exclosed peat soil microcosms, we identified 15 "responsive bioindicator OTUs". Three (mb661R) and two (A682R) OTUs had higher relative abundances at $0.1 \% \mathrm{CH}_{4}$, whereas six (mb661R) and four (A682R) OTUs had a higher relative abundance of transcripts at $1 \% \mathrm{CH}_{4}$ (Figures 7 and 8 and Supplementary Figures S10 and S11). 


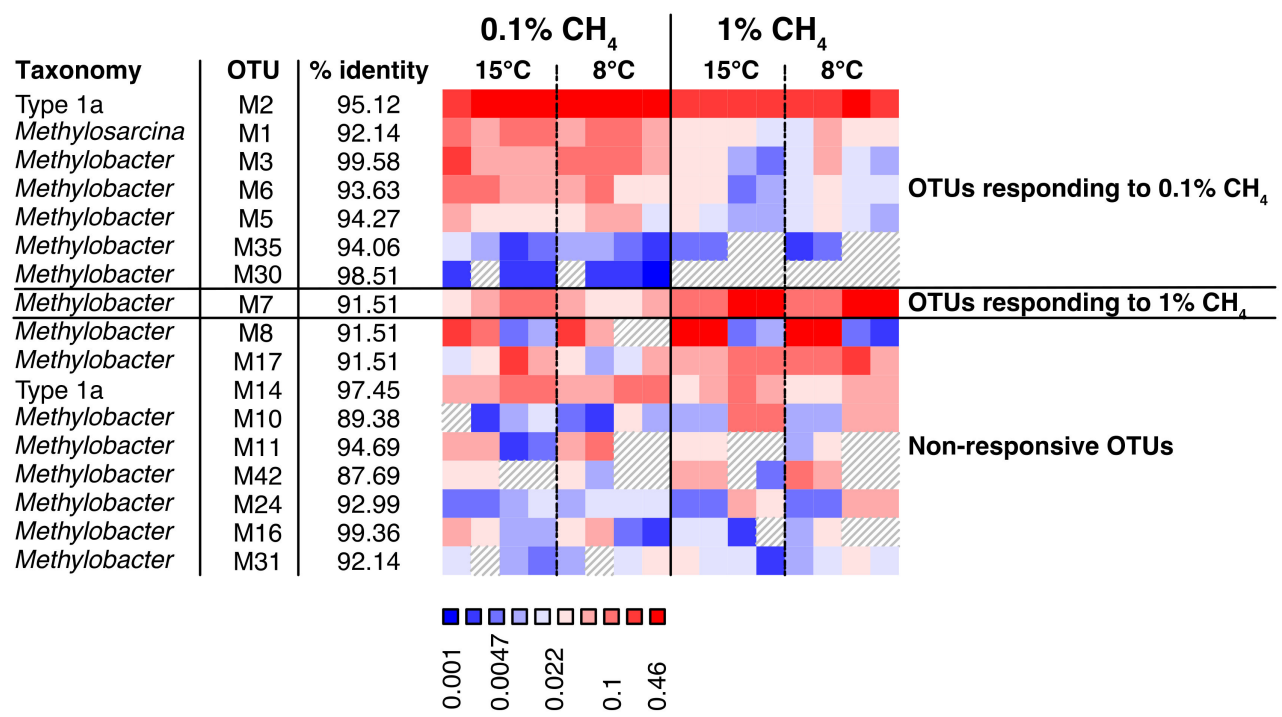

Figure 7. Relative abundances of $p m o A$ transcripts representing MOB OTUs (A189F/mb661R primer pair) from grazed peat soil microcosms after incubation at $0.1 \%$ and $1 \% \mathrm{CH}_{4}$ concentrations. OTUs with higher relative abundance at $0.1 \% \mathrm{CH}_{4}$ are shown in the first block (left), and those with higher relative abundance at $1 \% \mathrm{CH}_{4}$ in the second block (right). The non-responsive OTUs with the highest relative abundance are shown in the third block. The number of OTUs included in the figure make up $90 \%$ of the total MOB community transcription. OTUs are identified by the letter M (indicating that these are part of the mb661R dataset) and a number. The percentage of identity between the OTU and the best hit in the database is given next to the OTU identification. The highest possible taxonomic rank identified was chosen for each OTU. Relative abundances reach from low abundances (blue) to high (red).

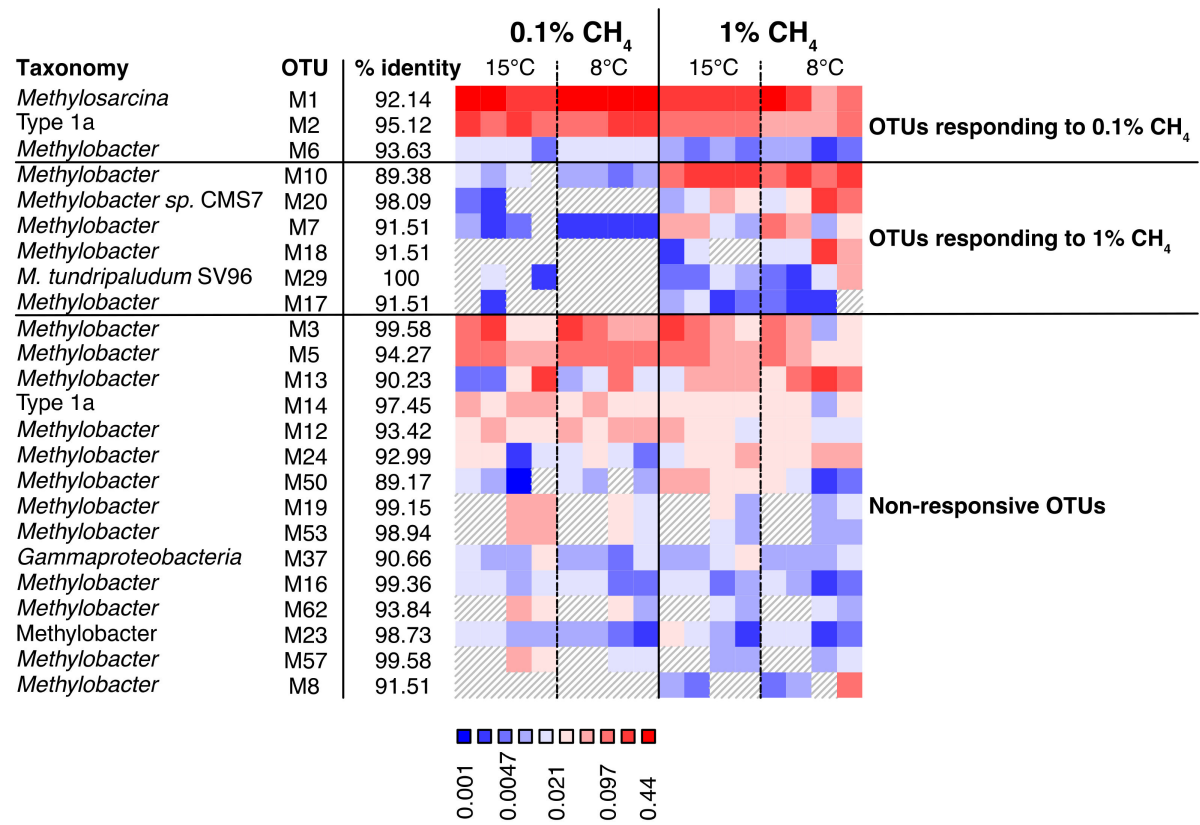

Figure 8. Relative abundances of $p m o A$ transcripts representing MOB OTUs (A189F/mb661R primer pair) from exclosed peat soil microcosms after incubation at $0.1 \%$ and $1 \% \mathrm{CH}_{4}$ concentrations. OTUs with higher relative abundance at $0.1 \% \mathrm{CH}_{4}$ are shown in the first block (left) and those with higher relative abundance at $1 \% \mathrm{CH}_{4}$ in the second block (right). The non-responsive OTUs with the highest relative abundance are shown in the third block. The number of OTUs included in the figure make up $90 \%$ of the total $\mathrm{MOB}$ community transcription. OTUs are identified by the letter $\mathrm{M}$ (indicating that these are part of the mb661R dataset) and a number. The percentage of identity between the OTU and the best hit in the database is given next to the OTU identification. The highest possible taxonomic rank identified was chosen for each OTU. Relative abundances reach from low abundances (blue) to high (red). 
The $p m o A$ sequences categorized as "unconditional bioindicator OTUs" were subsequently aligned with a set of reference sequences, including blast search hits and cultivated strains, and used to infer the phylogenetic relationships of the "unconditional bioindicator OTUs" from the mb661R and A682R datasets, respectively (Figure 9 and Supplementary Figure S12). The Methylobacter OTUs identified as "unconditional bioindicator OTUs" for $0.1 \% \mathrm{CH}_{4}$ clustered separately from those that were "unconditional bioindicator OTUs" for $1 \% \mathrm{CH}_{4}$ (Figure 9 and Supplementary Figure S12). The two Arctic strains, M. tundripaludum SV96 [32] and Methylobacter sp. CMS7 [31], clustered with two of the $1 \% \mathrm{CH}_{4}$ bioindicator OTUs, respectively (Figure 9), whereas the remaining bioindicator OTUs clustered with environmental sequences (including lake sediments and landfill cover soils rather than cultivated strains).

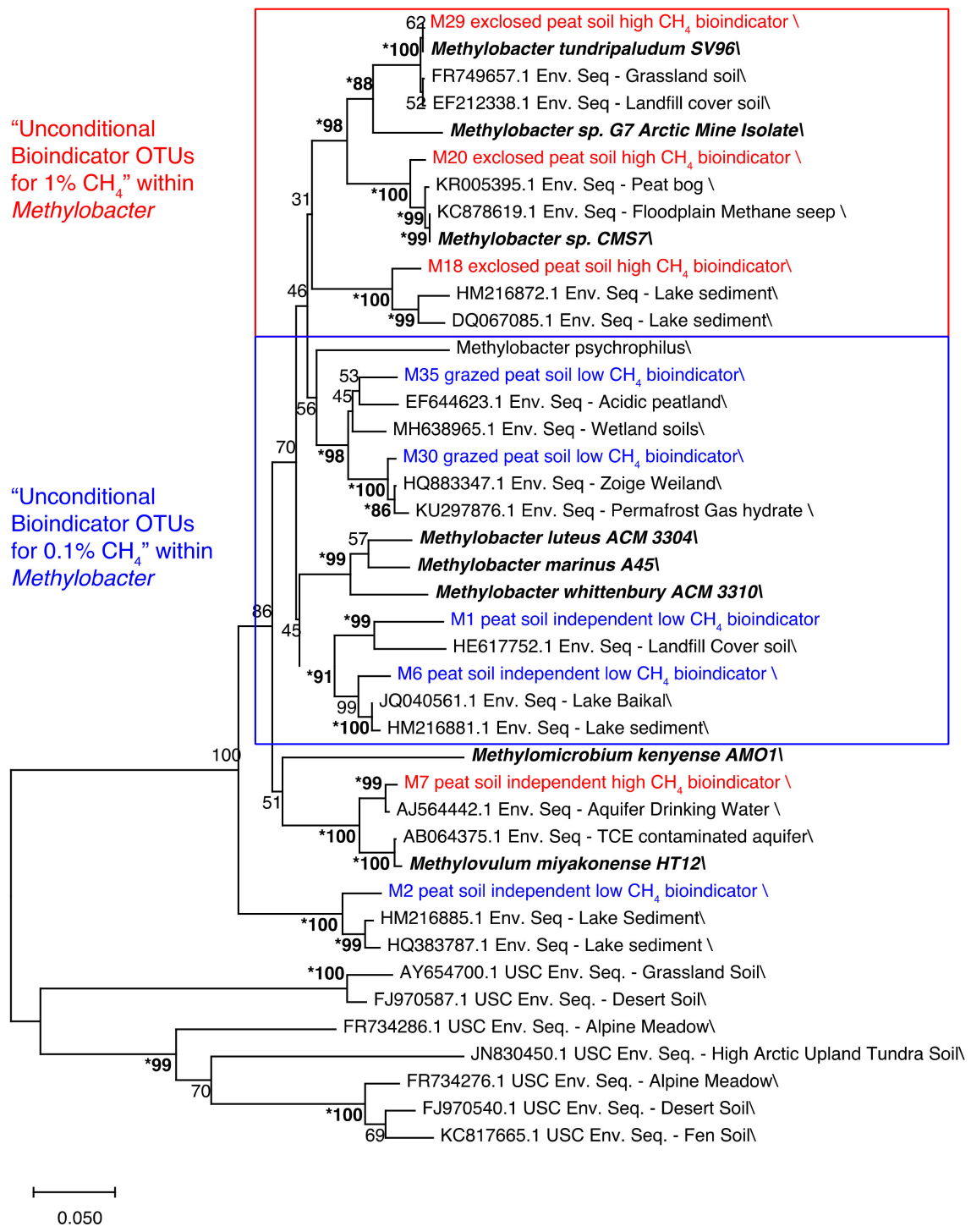

Figure 9. Phylogenetic representation of the "unconditional bioindicator OTUs" for $0.1 \% \mathrm{CH}_{4}$ (blue) and $1 \% \mathrm{CH}_{4}$ (red) incubations (mb661R dataset), cultivated MOB (bold, italic), and closely related environmental sequences retrieved from the NCBI GenBank. All OTUs included were identified as bioindicators both in the grazed and the exclosed peat soil microcosms, or in only one of the soil types, being absent from the other soil type. The first type is called "peat soil independent". The other type of OTUs, which were specifically assigned as bioindicators for one of the peat soil types, are labeled 
as either grazed or exclosed. The tree is based on a 456-nucleotide alignment, using the neighborjoining method with the Jukes-cantor correction and 500 bootstraps. The length of the branches is based on a scale of 0.05 changes per nucleotide. Bootstrap values of $>80$ in 3 models that were used to construct the tree (neighbor-joining, maximum likelihood, and minimum evolution) are marked with * and written in bold.

\section{Discussion}

\section{1. $\mathrm{CH}_{4}$ Response}

\subsubsection{Activity}

Higher $\mathrm{CH}_{4}$ concentrations led to higher $\mathrm{CH}_{4}$ oxidation rates immediately after addition, but the effect was stronger after a three-week incubation period at maintained $\mathrm{CH}_{4}$ concentrations. Thus, while the initial rates reflected the oxidation potential of the MOB community shortly after thawing, the latter rates were influenced by MOB growth, physiological acclimation, or community response. Responses of the MOB communities to increasing $\mathrm{CH}_{4}$ concentrations were shown in a study of lake overturn, where population shifts over several months corresponded with the ability of the MOB community to mitigate the majority of the $\mathrm{CH}_{4}$ [61]. In the same study, a growth response was also indicated in the MOB community, which was responsible for the oxidation of the $\mathrm{CH}_{4}$. Such an effect of $\mathrm{CH}_{4}$ concentrations on the MOB response and capacity was also shown in a study of atmospheric $\mathrm{CH}_{4}$ oxidation by conventional MOB, where conditioning with high $\mathrm{CH}_{4}$ concentrations allowed for atmospheric $\mathrm{CH}_{4}$ uptake [62]. The highest $\mathrm{CH}_{4}$ oxidation rates and strongest response after the three-week incubation in our experiment were observed in grazed peat soil microcosms. These soils contained in situ $\mathrm{CH}_{4}$ concentrations of up to $237.4 \mu \mathrm{M}\left(100.7-237.4 \mu \mathrm{M}\right.$ of dissolved $\mathrm{CH}_{4}$ at SV1) in the pore water at $5 \mathrm{~cm}$ and $2139.0 \mu \mathrm{M}\left(469.4-2139.0 \mu \mathrm{M}\right.$ dissolved $\left.\mathrm{CH}_{4}\right)$ at a depth of $10 \mathrm{~cm}$ [27]. In comparison, exclosed peat soils contained only up to $3.7 \mu \mathrm{M}$ of $\mathrm{CH}_{4}\left(0.4-3.7 \mu \mathrm{M} \mathrm{CH}_{4}\right.$ at SV1) at a depth of $10 \mathrm{~cm}$ and $578.0 \mu \mathrm{M}\left(0.53-578 \mu \mathrm{M}\right.$ of $\left.\mathrm{CH}_{4}\right)$ at a depth of $15 \mathrm{~cm}$. Thus, the $0.1 \%$ incubations (with a concentration of about 1.7-2 $\mu \mathrm{M}$ of dissolved $\mathrm{CH}_{4}$ ) were lower than in situ $\mathrm{CH}_{4}$ concentrations in grazed peat at depths of 5 and $10 \mathrm{~cm}$ and about in situ $\mathrm{CH}_{4}$ concentrations in exclosed soils at a depth of $10 \mathrm{~cm}$. The $1 \%$ incubations (with a concentration of about 17-20 $\mu \mathrm{M}$ of dissolved $\mathrm{CH}_{4}$ ) were lower than the in situ $\mathrm{CH}_{4}$ concentrations in grazed soils below $5 \mathrm{~cm}$, whereas they were higher than in situ $\mathrm{CH}_{4}$ concentrations of exclosed soils at a depth of $10 \mathrm{~cm}$. It should be noted that the samples for our experiments were collected from the surface (Exp I: 0-2 cm, Exp II: 0-4 cm) in grazed soils and above $10 \mathrm{~cm}$ (Exp I: 5-7 cm, Exp II: 4-8 cm). Thus, the microorganisms in these hotspots for $\mathrm{CH}_{4}$ oxidation would have been exposed to lower $\mathrm{CH}_{4}$ concentrations than indicated by the available in situ pore water $\mathrm{CH}_{4}$ measurements. Measurements at $0-5$ and $0-10 \mathrm{~cm}$ in the grazed and exclosed sites, respectively, were not possible due to the lack of pore water at these depths.

Nevertheless, these results show that the MOB responses were related to the dissolved $\mathrm{CH}_{4}$ concentrations in the respective soil pore waters, with stronger MOB responses to added $\mathrm{CH}_{4}$ in the soils with higher in situ $\mathrm{CH}_{4}$ concentrations.

\subsubsection{MOB Transcript Numbers}

We observed that a transcriptionally more active MOB community was responsible for the higher $\mathrm{CH}_{4}$ oxidation rates in the grazed peat soils compared to the exclosed peat soils. Positive correlations between $p m o A$ transcript numbers and $\mathrm{CH}_{4}$ oxidation rates have been shown before $[23,63]$. However, within each grazing treatment, we did not observe a correlation between pmoA transcript numbers and $\mathrm{CH}_{4}$ oxidation rates. Reasons for this may be changes in population sizes or changes in particulate methane monooxygenase kinetics due to a shift in the MOB community.

\subsubsection{MOB Transcript Composition}

$\mathrm{CH}_{4}$ concentration had a significant impact on the relative abundance of $p m o A$ transcripts for different members of the MOB community in both grazed and exclosed peat 
soils (Figure 5). These results corroborate previous results, suggesting that in situ $\mathrm{CH}_{4}$ concentrations shape the MOB community in the Solvatn peatland [27]. The relative abundances of Methylobacter OTUs were higher at a $1 \% \mathrm{CH}_{4}$ concentration in both the grazed and exclosed plots (Figure 6 and Supplementary Figure S9). In contrast to this, there was a lower relative abundance of Methylomicrobium and Methylosarcina OTU transcripts at a $1 \%$ $\mathrm{CH}_{4}$ concentration in both the grazed and exclosed plots. Methylobacter has been shown to thrive in colder, $\mathrm{CH}_{4}$-rich, environments with a neutral $\mathrm{pH}$, and our study confirms that this genus thrives when $\mathrm{CH}_{4}$ concentrations are high.

Furthermore, we identified a strong treatment-dependent community transcriptional response, with some OTUs responding positively to $1 \% \mathrm{CH}_{4}$ (the majority of reacting OTUs were Methylobacter), while others responded to $0.1 \% \mathrm{CH}_{4}$ (Figures 7 and 8 and Supplementary Figures S10 and S11). Interestingly, a larger number of OTUs responded to $0.1 \% \mathrm{CH}_{4}$ in the grazed peat soil microcosms, where in situ $\mathrm{CH}_{4}$ concentrations were the highest, while more OTUs responded to $1 \% \mathrm{CH}_{4}$ in the exclosed peat soil microcosms, which had the lowest in situ $\mathrm{CH}_{4}$ concentrations [27]. This suggests that high and low in situ $\mathrm{CH}_{4}$ concentrations select for different MOB strains, respectively, and that the largest group of strains respond to the condition that is most different from the in situ condition. We suspect that this is because the responding strains had low transcriptional activity in the original soil and became more active during steady exposure to a $0.1 \% \mathrm{CH}_{4}$ headspace concentration. Furthermore, our findings show that such effects are observable within three weeks and correlate with changes in the $\mathrm{CH}_{4}$ oxidation rates. This indicates the co-existence of closely related strains that prefer either high or low $\mathrm{CH}_{4}$ concentrations, respectively, and that these populations can replace each other within an Arctic summer. Similar observations were made in lakes, where changes in apparent half-saturation constants and $\mathrm{CH}_{4}$ uptake rates at the $\mathrm{CH}_{4}$ saturation correlated with changes in $p m o A$ expression and for which MOB strains (99\% identity) were responsible [61]. It is tempting to draw a line between which strains are active and use this as a basis for inferring whether the strains have high or low apparent affinities for $\mathrm{CH}_{4}$. However, cell numbers and cellular enzyme contents also influence uptake rates, and the relative contribution of enzyme kinetics, cell numbers, and cellular protein content to the observed rates remains unknown in most studies, including our own. Nevertheless, the different $\mathrm{CH}_{4}$ uptake rates seem to correspond with different compositions of active MOB strains.

\subsubsection{Phylogeny}

Most of the bioindicators belonged to the genus Methylobacter. Some of the "unconditional bioindicator OTUs" for $1 \% \mathrm{CH}_{4}$ clustered with high-Arctic Methylobacter isolates retrieved from $\mathrm{CH}_{4}$-rich ecosystems [31,32], while the phylogenetic clusters containing the "unconditional bioindicator OTUs" for $0.1 \% \mathrm{CH}_{4}$ did not contain closely related isolates. Atmospheric MOB are phylogenetically distinct but closely related to conventional MOB [24,64] and are characterized by a more efficient energy metabolism [44]. Similarly, phylogenetically different populations of ammonia-oxidizing Archaea are associated with different ammonia oxidation uptake rates $[65,66]$, and different ammonia oxidation kinetics reflect different life strategies [65]. Thus, the phylogenetic separation of OTUs with a higher abundance in the microcosms with high $\mathrm{CH}_{4}$ concentrations from those preferring low $\mathrm{CH}_{4}$ concentrations might indicate the existence of closely related but phylogenetically and functionally distinct Methylobacter strains that co-exist in the same environment. In addition to indicating the phylogenetic separation of function, these results also suggest a bias in enrichment and culturing approaches, as most isolates cluster with OTUs that are active at high $\mathrm{CH}_{4}$ concentrations.

\subsection{Temperature Response}

Rising temperatures are often affiliated with increases in metabolic activity [67], as shown by the temperature response in growth rates of pure cultures of methanotrophs [37]. In line with this, we did see significant effects of temperature on cellular $\mathrm{CH}_{4}$ oxidation 
rates in $M$. tundripaludum SV96, although the differences were minor at $0.1 \% \mathrm{CH}_{4}$. In comparison, temperature had small and inconsistent effects on soil $\mathrm{CH}_{4}$ oxidation rates and $p m o A$ transcript abundances at both $0.1 \%$ and $1 \% \mathrm{CH}_{4}$. Inconsistent temperature effects on $\mathrm{CH}_{4}$ oxidation might be caused by several factors, such as changes in cell growth, growth efficiency, cell numbers, cellular protein contents, and types of active MOB strains, all of which may be affected by substrate and nutrient concentrations. In a study of Arctic lakes, $\mathrm{CH}_{4}$ oxidation rates were not increasing with increasing temperature when the substrate was limiting [38]. Thus, there might be a physiological response to temperature that, due to $\mathrm{CH}_{4}$ limitation, looks like a lack of temperature response. This could be the case in some of our microcosms, particularly at the lowest $(0.1 \%) \mathrm{CH}_{4}$ concentration, possibly explaining the small temperature effect seen at $0.1 \% \mathrm{CH}_{4}$ in the experiment with $M$. tundripaludum SV96. $\mathrm{CH}_{4}$ oxidation has frequently been observed as being less temperature-sensitive than $\mathrm{CH}_{4}$ production, but this phenomenon has not yet been explained [35]. Future studies should, therefore, address intracellular physiological responses in MOB at different temperatures and not only quantify $\mathrm{CH}_{4}$ oxidation rates and growth. Temperatures from $8^{\circ} \mathrm{C}$ to $15^{\circ} \mathrm{C}$ do occur in the topsoil on warm summer days in Svalbard [27], and although the community must be physiologically capable of responding to such temperature changes, we are still not aware of how.

Shifts in the active members of the MOB community may also influence the temperature response of a microbial community, but we did not observe any consistent transcriptional shifts among the active members with a change in temperature. Thus, within the temperature range covered in this study, shifts in the transcriptionally active community did not seem to be a significant response.

\section{Conclusions}

We found that MOB in Arctic peat soils from Svalbard respond to changes in $\mathrm{CH}_{4}$ concentrations, but the nature of the response depends on whether the peat has been exposed to herbivory. Herbivory "conditioning" simultaneously influenced the presence and activity of different $\mathrm{MOB}$ strains, community $\mathrm{CH}_{4}$ oxidation, and the effect of increased $\mathrm{CH}_{4}$ concentration on $\mathrm{CH}_{4}$ oxidation rates. Temperature, on the other hand, had only minor effects on the MOB community and its $\mathrm{CH}_{4}$ uptake. However, as $\mathrm{CH}_{4}$ production is expected to increase with higher temperatures, we hypothesize that the resulting higher peat soil $\mathrm{CH}_{4}$ concentrations will influence $\mathrm{MOB}$ activity and $\mathrm{CH}_{4}$ oxidation potential, but this shift will be influenced by the extent of the herbivory.

Supplementary Materials: The following are available online at https:/ / www.mdpi.com/article/ 10.3390/microorganisms9102080/s1, Figure S1: $\mathrm{CH}_{4}$ oxidation rates from Exp II emphasizing the comparison between $0.1 \%$ and $1 \%$ headspace $\mathrm{CH}_{4}$ concentrations. Figure S2: $\mathrm{CH}_{4}$ oxidation rates from Exp I before and and after the three-week incubation. Figure S3: $\mathrm{CH}_{4}$ oxidation rates from Exp II before and and after the three-week incubation. Figure S4: $\mathrm{CH}_{4}$ oxidation rates from Exp II emphasizing the comparison between 8 and $15^{\circ} \mathrm{C}$. Figure S5: $\mathrm{CH}_{4}$ oxidation rates from Exp I emphasizing the comparison between $8^{\circ} \mathrm{C}$ and $15^{\circ} \mathrm{C}$ (corrected for dissolved $\mathrm{CH}_{4}$ ). Figure S6: $\mathrm{CH}_{4}$ oxidation rates from Exp II emphasizing the comparison between $8{ }^{\circ} \mathrm{C}$ and $15{ }^{\circ} \mathrm{C}$ (corrected for dissolved $\mathrm{CH}_{4}$ ). Figure S7: $\mathrm{CH}_{4}$ oxidation per cell for Methylobacter tundripaludum SV96. Table S1: Number of sequences and OTUs at the different stages of the bioinformatic pipeline. Figure S8: Redundancy analysis of the effect of $\mathrm{CH}_{4}$ concentration and temperature on the MOB communities after incubation ( $p m o A$ transcripts using the A189F/A682R primer pair). Figure S9: Distribution of MOB taxa (A189F/A682R primer set) in grazed and exclosed peat soils after incubation at $0.1 \% \mathrm{CH}_{4}$ and at $1 \% \mathrm{CH}_{4}$. Figure S10: Relative abundances of $p m o A$ transcripts representing MOB OTUs (A189F/A682R primer pair) from grazed peat soil microcosms after incubation at $0.1 \%$ and $1 \% \mathrm{CH}_{4}$ concentration. Figure S11: Relative abundances of $p m o A$ transcripts representing MOB OTUs (A189F/A682R primer pair) from exclosed peat soil microcosms after incubation at $0.1 \%$ and $1 \% \mathrm{CH}_{4}$ concentration. Figure S12: Phylogenetic representation of the "unconditional bioindicator OTUs" for $0.1 \% \mathrm{CH}_{4}$ (blue) and $1 \% \mathrm{CH}_{4}$ (red) incubations, cultivated MOB (bold, italic) and closely related environmental sequences retrieved from the NCBI GenBank 
Author Contributions: E.M.R. conceived the study with input from A.T.T and M.M.S.; E.M.R., C.H. and M.M.S. established the microcosm experiments. C.H. conducted the microcosm experiments and E.M.R. the growth and rate measurements in pure culture; C.H. extracted the RNA, prepared them for sequencing, and ran the qPCR experiments with assistance from E.M.R.; E.M.R and A.T.T. analyzed the gas uptake rates.; C.V.W.S. analyzed the sequences and performed the statistics; E.M.R. wrote the manuscript with input from all authors. All authors have read the manuscript and agreed to publish the manuscript in its present state.

Funding: The funding for this study was provided by NORRUSS (233645/H30) and Svalbard Science Forum (AFG grant: 256933/E10) from the Research Council of Norway. ATT was supported by the Research Council of Norway FRIPRO Mobility Grant Project Time and Energy 251027/RU, cofounded by ERC under Marie Curie Grant 606895, and Tromsø Research Foundation starting grant project Cells in the Cold 16_SG_ATT. CVWS was supported by the Research Council of Norway, projects BiodivERsA (270252/E50) and ERAnet-LAC(256132/H30).

Data Availability Statement: The data presented in this study are openly available in the European Nucleotide Archive (ENA), project PRJEB48225.

Conflicts of Interest: The authors declare no conflict of interest.

\section{References}

1. Kuijper, D.P.J.; Bakker, J.P.; Cooper, E.J.; Ubels, R.; Jónsdóttir, I.S.; Loonen, M.J.J.E. Intensive grazing by Barnacle geese depletes High Arctic seed bank. Can. J. Bot. 2006, 84, 995-1004. [CrossRef]

2. Jefferies, R.L.; Rockwell, R.F. Foraging geese, vegetation loss and soil degradation in an Arctic salt marsh. Appl. Veg. Sci. 2002, 5, 7-16. [CrossRef]

3. Handa, I.T.; Harmsen, R.; Jefferies, R.L. Patterns of vegetation change and the recovery potential of degraded areas in a coastal marsh system of the Hudson Bay lowlands. J. Ecol. 2002, 90, 86-99. [CrossRef]

4. Hessen, D.O.; Tombre, I.M.; van Geest, G.; Alfsnes, K. Global change and ecosystem connectivity: How geese link fields of central Europe to eutrophication of Arctic freshwaters. Ambio 2017, 46, 40-47. [CrossRef]

5. Tombre, I.M.; Oudman, T.; Shimmings, P.; Griffin, L.; Prop, J. Northward range expansion in spring-staging barnacle geese is a response to climate change and population growth, mediated by individual experience. Glob. Chang. Biol. 2019, 25, 3680-3693. [CrossRef]

6. Bardgett, R.D.; Wardle, D.A. Herbivore-mediated linkages between aboveground and belowground communities. Ecology 2003, 84, 2258-2268. [CrossRef]

7. Wardle, D.A.; Bardgett, R.D.; Klironomos, J.N.; Setälä, H.; Van Der Putten, W.H.; Wall, D.H. Ecological linkages between aboveground and belowground biota. Science 2004, 304, 1629-1633. [CrossRef]

8. Foley, K.M.; Beard, K.H.; Atwood, T.B.; Waring, B.G. Herbivory changes soil microbial communities and greenhouse gas fluxes in a high-latitude wetland. Microb. Ecol. 2021, 1-10. [CrossRef]

9. Falk, J.M.; Schmidt, N.M.; Christensen, T.R.; Ström, L. Large herbivore grazing affects the vegetation structure and greenhouse gas balance in a high Arctic mire. Environ. Res. Lett. 2015, 10, 45001. [CrossRef]

10. Winton, R.S.; Richardson, C.J. Top-down control of methane emission and nitrogen cycling by waterfowl. Ecology 2017, 98, 265-277. [CrossRef] [PubMed]

11. Kelsey, K.C.; Leffler, A.J.; Beard, K.H.; Schmutz, J.A.; Choi, R.T.; Welker, J.M. Interactions among vegetation, climate, and herbivory control greenhouse gas fluxes in a subarctic coastal wetland. J. Geophys. Res. Biogeosciences 2016, 121, 2960-2975. [CrossRef]

12. Sjögersten, S.; van der Wal, R.; Loonen, M.J.J.E.; Woodin, S.J. Recovery of ecosystem carbon fluxes and storage from herbivory. Biogeochemistry 2011, 106, 357-370. [CrossRef]

13. Bender, K.M.; Svenning, M.M.; Hu, Y.; Richter, A.; Schückel, J.; Jørgensen, B.; Liebner, S.; Tveit, A.T. Microbial responses to herbivory-induced vegetation changes in a high-Arctic peatland. Polar Biol. 2021, 44, 899-911. [CrossRef]

14. Cohen, J.; Screen, J.A.; Furtado, J.C.; Barlow, M.; Whittleston, D.; Coumou, D.; Francis, J.; Dethloff, K.; Entekhabi, D.; Overland, J.; et al. Recent Arctic amplification and extreme mid-latitude weather. Nat. Geosci. 2014, 7, 627-637. [CrossRef]

15. Francis, J.A.; Vavrus, S.J.; Cohen, J. Amplified Arctic warming and mid-latitude weather: New perspectives on emerging connections. Wiley Interdiscip. Rev. Clim. Chang. 2017, 8, 1-11. [CrossRef]

16. Serreze, M.C.; Barry, R.G. Processes and impacts of Arctic amplification: A research synthesis. Glob. Planet. Change 2011, 77, 85-96. [CrossRef]

17. Tarnocai, C.; Canadell, J.G.; Schuur, E.A.G.; Kuhry, P.; Mazhitova, G.; Zimov, S. Soil organic carbon pools in the northern circumpolar permafrost region. Glob. Biogeochem. Cycles 2009, 23, 1-11. [CrossRef]

18. Tveit, A.T.; Urich, T.; Frenzel, P.; Svenning, M.M. Metabolic and trophic interactions modulate methane production by Arctic peat microbiota in response to warming. Proc. Natl. Acad. Sci. USA 2015, 112, E2507-E2516. [CrossRef] 
19. Metje, M.; Frenzel, P. Methanogenesis and methanogenic pathways in a peat from subarctic permafrost. Environ. Microbiol. 2007, 9, 954-964. [CrossRef]

20. Metje, M.; Frenzel, P. Effect of temperature on anaerobic ethanol oxidation and methanogenesis in acidic peat from a Northern Wetland. Appl. Environ. Microbiol. 2005, 71, 8191-8200. [CrossRef] [PubMed]

21. Høj, L.; Olsen, R.A.; Torsvik, V.L. Archaeal communities in High Arctic wetlands at Spitsbergen, Norway $\left(78^{\circ} \mathrm{N}\right)$ as characterized by $16 \mathrm{~S}$ rRNA gene fingerprinting. FEMS Microbiol. Ecol. 2005, 53, 89-101. [CrossRef]

22. Brune, A.; Frenzel, P.; Cypionka, H. Life at the oxic-anoxic interface: Microbial activities and adaptations. FEMS Microbiol. Rev. 2000, 24, 691-710. [CrossRef]

23. Reim, A.; Lüke, C.; Krause, S.; Pratscher, J.; Frenzel, P. One millimetre makes the difference: High-resolution analysis of methaneoxidizing bacteria and their specific activity at the oxic-anoxic interface in a flooded paddy soil. ISME J. 2012, 6, 2128-2139. [CrossRef] [PubMed]

24. Knief, C. Diversity and habitat preferences of cultivated and uncultivated aerobic methanotrophic bacteria evaluated based on pmoA as molecular marker. Front. Microbiol. 2015, 6, 1346. [CrossRef]

25. Wartiainen, I.; Hestnes, A.G.; Svenning, M.M. Methanotrophic diversity in high arctic wetlands on the islands of Svalbard (Norway)-denaturing gradient gel electrophoresis analysis of soil DNA and enrichment cultures. Can. J. Microbiol. 2003, 49, 602-612. [CrossRef] [PubMed]

26. Martineau, C.; Whyte, L.G.; Greer, C.W. Stable isotope probing analysis of the diversity and activity of Methanotrophic bacteria in soils from the Canadian high Arctic. Appl. Environ. Microbiol. 2010, 76, 5773-5784. [CrossRef] [PubMed]

27. Rainer, E.M.; Seppey, C.V.W.; Tveit, A.T.; Svenning, M.M. Methanotroph populations and CH4 oxidation potentials in High Arctic peat are altered by herbivory induced vegetation change. FEMS Microbiol. Ecol. 2020, 96, 1-12. [CrossRef] [PubMed]

28. Tveit, A.T.; Kiss, A.; Winkel, M.; Horn, F.; Hájek, T.; Svenning, M.M.; Wagner, D.; Liebner, S. Environmental patterns of brown moss- and Sphagnum-associated microbial communities. Sci. Rep. 2020, 10, 1-16. [CrossRef] [PubMed]

29. Dedysh, S.N.; Didriksen, A.; Danilova, O.V.; Belova, S.E.; Liebner, S.; Svenning, M.M. Methylocapsa palsarum sp. nov., a methanotroph isolated from a subarctic discontinuous permafrost ecosystem. Int. J. Syst. Evol. Microbiol. 2015, 65, 3618-3624. [CrossRef]

30. Dedysh, S.N.; Berestovskaya, Y.Y.; Vasylieva, L.V.; Belova, S.E.; Khmelenina, V.N.; Suzina, N.E.; Trotsenko, Y.A.; Liesack, W.; Zavarzin, G.A. Methylocella tundrae sp. nov., a novel methanotrophic bacterium from acidic tundra peatlands. Int. J. Syst. Evol. Microbiol. 2004, 54, 151-156. [CrossRef] [PubMed]

31. Belova, S.E.; Oshkin, I.Y.; Glagolev, M.V.; Lapshina, E.D.; Maksyutov, S.S.; Dedysh, S.N. Methanotrophic bacteria in cold seeps of the floodplains of northern rivers. Microbiology 2013, 82, 743-750. [CrossRef]

32. Wartiainen, I.; Hestnes, A.G.; McDonald, I.R.; Svenning, M.M. Methylobacter tundripaludum sp. nov., a methane-oxidizing bacterium from Arctic wetland soil on the Svalbard islands, Norway (78 ${ }^{\circ}$ N). Int. J. Syst. Evol. Microbiol. 2006, 56, 109-113. [CrossRef]

33. Berestovskaya, Y.Y.; Vasil'eva, L.V.; Chestnykh, O.V.; Zavarzin, G.A. Methanotrophs of the psychrophilic microbial community of the Russian arctic tundra. Microbiology 2002, 71, 460-466. [CrossRef]

34. Einola, J.K.M.; Kettunen, R.H.; Rintala, J.A. Responses of methane oxidation to temperature and water content in cover soil of a boreal landfill. Soil Biol. Biochem. 2007, 39, 1156-1164. [CrossRef]

35. Zheng, J.; RoyChowdhury, T.; Yang, Z.; Gu, B.; Wullschleger, S.D.; Graham, D.E. Impacts of temperature and soil characteristics on methane production and oxidation in Arctic tundra. Biogeosciences 2018, 15, 6621-6635. [CrossRef]

36. King, G.M.; Adamsen, A.P.S. Effects of temperature on methane consumption in a forest soil and in pure cultures of the methanotroph Methylomonas rubra. Appl. Environ. Microbiol. 1992, 58, 2758-2763. [CrossRef]

37. Kevbrina, M.V.; Okhapkina, A.A.; Akhlynin, D.S.; Kravchenko, I.K.; Nozhevnikova, A.N.; Gal'chenko, V.F. Growth of mesophilic methanotrophs at low temperatures. Microbiology 2001, 70, 384-391. [CrossRef]

38. Lofton, D.D.; Whalen, S.C.; Hershey, A.E. Effect of temperature on methane dynamics and evaluation of methane oxidation kinetics in shallow Arctic Alaskan lakes. Hydrobiologia 2014, 721, 209-222. [CrossRef]

39. Zeng, L.; Tian, J.; Chen, H.; Wu, N.; Yan, Z.; Du, L.; Shen, Y.; Wang, X. Changes in methane oxidation ability and methanotrophic community composition across different climatic zones. J. Soils Sediments 2019, 19, 533-543. [CrossRef]

40. Solheim, B.; Endal, A.; Vigstad, H. Nitrogen fixation in Arctic vegetation and soils from Svalbard, Norway. Polar Biol. 1996, 16, 35-40. [CrossRef]

41. Graef, C.; Hestnes, A.G.; Svenning, M.M.; Frenzel, P. The active methanotrophic community in a wetland from the High Arctic. Environ. Microbiol. Rep. 2011, 3, 466-472. [CrossRef]

42. Tveit, A.; Schwacke, R.; Svenning, M.M.; Urich, T. Organic carbon transformations in high-Arctic peat soils: Key functions and microorganisms. ISME J. 2013, 7, 299-311. [CrossRef]

43. Niemann, H.; Steinle, L.; Blees, J.; Bussmann, I.; Treude, T.; Krause, S.; Elvert, M.; Lehmann, M.F. Toxic effects of lab-grade butyl rubber stoppers on aerobic methane oxidation. Limnol. Oceanogr. Methods 2015, 13, 40-52. [CrossRef]

44. Tveit, A.T.; Schmider, T.; Hestnes, A.G.; Lindgren, M.; Didriksen, A.; Svenning, M.M. Simultaneous oxidation of atmospheric methane, carbon monoxide and hydrogen for bacterial growth. Microorganisms 2021, 9, 153. [CrossRef] [PubMed]

45. Whittenbury, R.; Phillips, K.C.; Wilkinson, J.F. Enrichment, Isolation and Some Properties of Methane-utilizing Bacteria. J. Gen. Microbiol. 1970, 61, 205-218. [CrossRef] [PubMed] 
46. Tays, C.; Guarnieri, M.T.; Sauvageau, D.; Stein, L.Y. Combined effects of carbon and nitrogen source to optimize growth of proteobacterial methanotrophs. Front. Microbiol. 2018, 9, 1-14. [CrossRef]

47. Urich, T.; Lanzén, A.; Qi, J.; Huson, D.H.; Schleper, C.; Schuster, S.C. Simultaneous assessment of soil microbial community structure and function through analysis of the meta-transcriptome. PLoS ONE 2008, 3, e2527. [CrossRef]

48. Costello, A.M.; Lidstrom, M.E. Molecular characterization of functional and phylogenetic genes from natural populations of methanotrophs in lake sediments. Appl. Environ. Microbiol. 1999, 65, 5066-5074. [CrossRef]

49. Holmes, A.J.; Costello, A.; Lidstrom, M.E.; Murrell, J.C. Evidence that particulate methane monooxygenasre and ammonia monooxygenase may be related. FEMS Microbiol. Lett. 1995, 132, 203-208. [CrossRef]

50. Henneberger, R.; Lüke, C.; Mosberger, L.; Schroth, M.H. Structure and function of methanotrophic communities in a landfill-cover soil. FEMS Microbiol. Ecol. 2012, 81, 52-65. [CrossRef]

51. Wen, X.; Yang, S.; Liebner, S. Evaluation and update of cutoff values for methanotrophic pmoA gene sequences. Arch. Microbiol. 2016, 198, 629-636. [CrossRef]

52. Magoč, T.; Salzberg, S.L. FLASH: Fast length adjustment of short reads to improve genome assemblies. Bioinformatics 2011, 27, 2957-2963. [CrossRef]

53. Rognes, T.; Flouri, T.; Nichols, B.; Quince, C.; Mahé, F. VSEARCH: A versatile open source tool for metagenomics. PeerJ 2016, 4, e2584. [CrossRef]

54. Mahé, F.; Rognes, T.; Quince, C.; de Vargas, C.; Dunthorn, M. Swarm: Robust and fast clustering method for amplicon-based studies. PeerJ 2014, 2, e593. [CrossRef]

55. Pearson, W.R. Flexible Sequence Similarity Searching with the FASTA3 Program Package. In Methods in Molecular Biology; Misener, S., Krawetz, S.A., Eds.; Humana Press: Totowa, NJ, USA, 2000; pp. 185-219.

56. Anderson, M.J.; Ellingsen, K.E.; McArdle, B.H. Multivariate dispersion as a measure of beta diversity. Ecol. Lett. 2006, 9, 683-693. [CrossRef] [PubMed]

57. Oksanen, J.; Blanchet, F.G.; Friendly, M.; Kindt, R.; Legendre, P.; McGlinn, D.; Minchin, P.R.; O’Hara, R.B.; Simpson, G.L.; Solymos, P.; et al. Vegan: Community Ecology Package. 2018. Available online: https://cran.r-project.org/web/packages/ vegan/index.html (accessed on 24 January 2018).

58. Roberts, D. Package'labdsv'. 2016. Available online: https://cran.r-project.org/web/packages/labdsv/labdsv.pdf (accessed on 24 January 2016).

59. Kumar, S.; Stecher, G.; Li, M.; Knyaz, C.; Tamura, K. MEGA X: Molecular Evolutionary Genetics Analysis across computing platforms. Mol. Biol. Evol. 2018, 35, 1547-1549. [CrossRef]

60. Edgar, R.C. MUSCLE: Multiple sequence alignment with high accuracy and high throughput. Nucleic Acids Res. 2004, 32, 1792-1797. [CrossRef] [PubMed]

61. Mayr, M.J.; Zimmermann, M.; Dey, J.; Brand, A.; Wehrli, B.; Bürgmann, H. Growth and rapid succession of methanotrophs effectively limit methane release during lake overturn. Commun. Biol. 2020, 3, 1-9. [CrossRef]

62. Cai, Y.; Zheng, Y.; Bodelier, P.L.E.; Conrad, R.; Jia, Z. Conventional methanotrophs are responsible for atmospheric methane oxidation in paddy soils. Nat. Commun. 2016, 7, 1-10. [CrossRef] [PubMed]

63. Siljanen, H.M.P.; Saari, A.; Bodrossy, L.; Martikainen, P.J. Seasonal variation in the function and diversity of methanotrophs in the littoral wetland of a boreal eutrophic lake. FEMS Microbiol. Ecol. 2012, 80, 548-555. [CrossRef]

64. Tveit, A.T.; Hestnes, A.G.; Robinson, S.L.; Schintlmeister, A.; Dedysh, S.N.; Jehmlich, N.; Von Bergen, M.; Herbold, C.; Wagner, M.; Richter, A.; et al. Widespread soil bacterium that oxidizes atmospheric methane. Proc. Natl. Acad. Sci. USA 2019, 116, 8515-8524. [CrossRef] [PubMed]

65. Kits, K.D.; Sedlacek, C.J.; Lebedeva, E.V.; Han, P.; Bulaev, A.; Pjevac, P.; Daebeler, A.; Romano, S.; Albertsen, M.; Stein, L.Y.; et al. Kinetic analysis of a complete nitrifier reveals an oligotrophic lifestyle. Nature 2017, 549, 269-272. [CrossRef] [PubMed]

66. Alves, R.J.E.; Wanek, W.; Zappe, A.; Richter, A.; Svenning, M.M.; Schleper, C.; Urich, T. Nitrification rates in Arctic soils are associated with functionally distinct populations of ammonia-oxidizing archaea. ISME J. 2013, 7, 1620-1631. [CrossRef] [PubMed]

67. Dijkstra, P.; Thomas, S.C.; Heinrich, P.L.; Koch, G.W.; Schwartz, E.; Hungate, B.A. Effect of temperature on metabolic activity of intact microbial communities: Evidence for altered metabolic pathway activity but not for increased maintenance respiration and reduced carbon use efficiency. Soil Biol. Biochem. 2011, 43, 2023-2031. [CrossRef] 